\title{
क्जि
}

Autarquia associada à Universidade de São Paulo

\section{AVALIAÇÃO DOS EFEITOS DA RADIAÇÃO IONIZANTE NOS ASPECTOS MICROBIOLÓGICOS, FÍSICO-QUÍMICOS E SENSORIAIS DE SORVETES}

Vladimir Dias Rogovschi

Tese apresentada como parte dos requisitos para a obtenção do Grau de Doutor em Ciências na Área de Tecnologia Nuclear Aplicações

Orientadora: Dra. Susy Frey Sabato 
Dedico a todas as pessoas que direta ou indiretamente contribuíram para que esse trabalho fosse realizado. 


\section{AGRADECIMENTOS}

Agradeço à Dra. Susy Frey Sabato, pela oportunidade de realizar esse trabalho.

Ao IPEN, especialmente ao Centro de Tecnologia das Radiações, representado pela Dra. Margarida Hamada gerente do CTR.

Ao Dr. Wilson Aparecido Parejo Calvo pelo constante apoio e pré-disposição em ajudar e na busca por soluções;

Ao Dr. Pablo Antônio Vasquez Salvador por todo auxílio prestado na irradiação das amostras;

À Dra. Maria Raquel Manhani por todo apoio na realização desse trabalho;

À Comissão Nacional de Energia Nuclear, pela concessão da bolsa de estudo; 
“Obstáculos são aqueles perigos que você vê quando tira os olhos de seu objetivo"

Henry Ford 


\section{AVALIAÇÃO DOS EFEITOS DA RADIAÇÃO IONIZANTE NOS ASPECTOS MICROBIOLÓGICOS, FÍSICO-QUÍMICOS E SENSORIAIS DE SORVETES}

\section{Resumo}

O sorvete é definido como gelado comestível obtido a partir da emulsão de gorduras e proteínas ou de uma mistura de água e açúcar, podendo ser adicionados outros ingredientes desde que não descaracterizem o produto. É considerado um alimento de alto valor nutricional, fornecendo lipídios, carboidratos, proteínas, cálcio, fósforo e outros minerais e vitaminas (A, B1, B2, B6, C, D, E e K), sendo um dos produtos mais importante e de maior interesse para as indústrias de derivados lácteos, devido à grande demanda pela população. As doenças relacionadas ao consumo de alimentos são consideradas um dos problemas mais relevantes. Diversos surtos alimentares relacionados a contaminação microbiológica de sorvetes foram relatados nas últimas décadas em países da Ásia, Europa e América. Acredita-se que o sorvete, por ser um alimento congelado, não apresenta riscos à saúde da população. Porém, ele é considerado um excelente meio para o crescimento de microrganismos, em função da sua composição, pH próximo a neutralidade e longo período de armazenamento. O objetivo deste trabalho foi avaliar os aspectos microbiológicos, sensoriais e físico-químicos de sorvetes de creme. As amostras de sorvete de creme foram irradiadas com raios gama $\left({ }^{60} \mathrm{Co}\right)$, nas doses de 1,0kGy, 2,0kGy, 3,0kGy e 4,0kGy. As amostras destinadas à inoculação de Staphylococcus aureus (cepa ATCC 6538), Escherichia coli (cepa ATCC 11229) e Salmonella abaetetuba (cepa ATCC 35640) foram irradiadas com doses de 1,0, 2,0 e 3,0kGy. Conclui-se que as amostras irradiadas com 3,0kGy apresentaram uma redução em níveis não detectáveis para a maioria dos microrganismos estudados. O uso da radiação gama afetou a textura do sorvete, assim como os parâmetros de cor na análise colorimétrica. Os resultados da análise sensorial demonstram que a dose de melhor aceitação foi a de 3,0kGy. 


\title{
EVALUATION OF THE IONIZING RADIATION EFFECTS IN MICROBIOLOGY, PHYSICAL AND CHEMICAL AND SENSORY ASPECTS OF ICE CREAM
}

\begin{abstract}
The ice cream is defined as an emulsion of fats and proteins or a mixture of water and sugar, other ingredients may be added provided since they do not affect the product. It is considered a food of high nutritional value, providing lipids, carbohydrates, protein, calcium, phosphorus, and other minerals and vitamins (A, $B 1, B 2, B 6, C, D, E$ and $K$ ), and it is considered one of the most important products and higher interest to the dairy industry due to great demand by the consumers. The diseases related to food consumption are considered one of the most significant problems. Several outbreaks related to microbiological contamination of ice cream have been reported in recent decades in Asia, Europe and America. It is believed that the ice cream, as a frozen food, presents no risk to the population health. However, it is considered an excellent environment for the growth of microorganisms due to its composition, $\mathrm{pH}$ close to neutrality and long storage period. The aim of this study was to evaluate the microbiological, sensory and physicochemical aspects of ice cream. The ice cream samples were irradiated with gamma rays $\left({ }^{60} \mathrm{Co}\right)$ with the doses of $1.0 \mathrm{kGy}, 2.0 \mathrm{kGy}, 3.0 \mathrm{kGy}$ and $4.0 \mathrm{kGy}$. The samples intended for the inoculation of Staphylococcus aureus (ATCC 6538), Escherichia coli (ATCC 11229) and Salmonella abaetetuba (ATCC 35640) have been irradiated with doses of 1.0, 2.0 and 3.0kGy. It can be concluded that the dose of $3.0 \mathrm{kGy}$ was adequate to reduce most of the studied microorganisms to undetected levels. The use of gamma radiation affected the texture and the parameters of the colorimetric analyses of the ice cream. The results of the sensorial analyses showed that the better accepted dose was 3.0kGy.
\end{abstract}




\section{SUMÁRIO}

Página

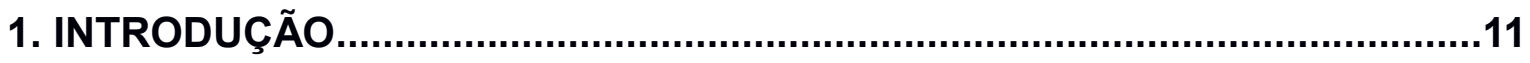

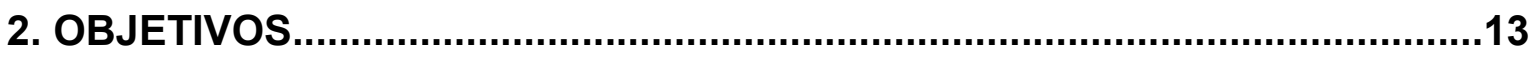

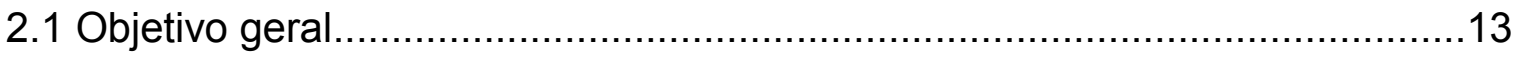

2.2 Objetivos específicos.................................................................... 13

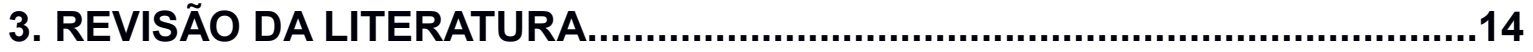

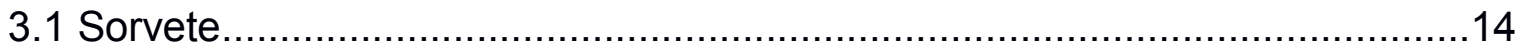

3.1.1 Definição de sorvete.................................................................. 14

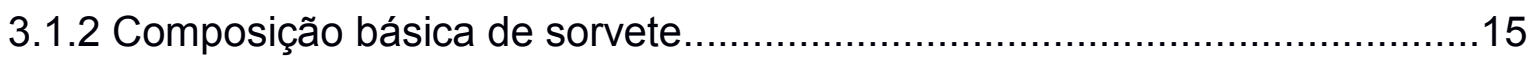

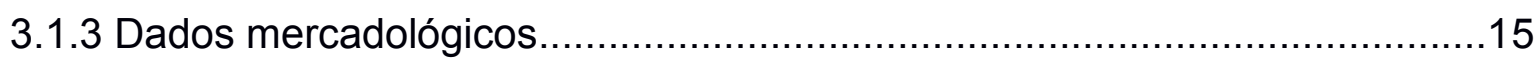

3.1.4 Características microbiológicas de sorvete.........................................19

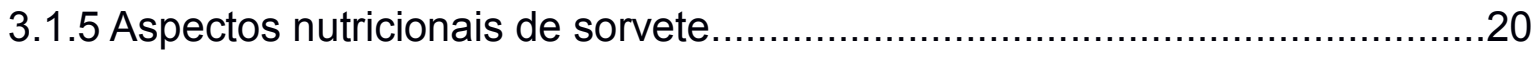

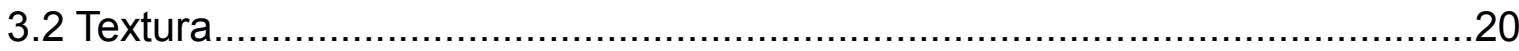

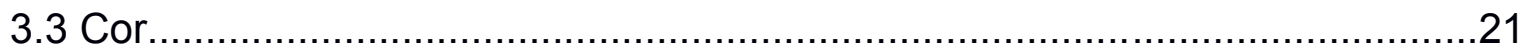

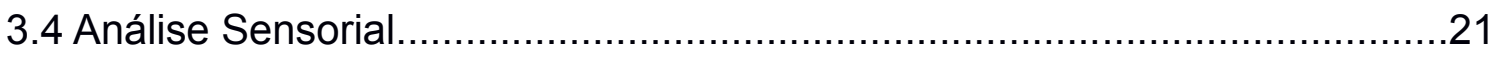

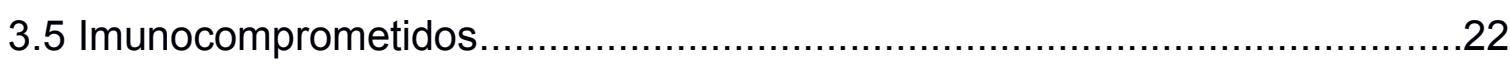

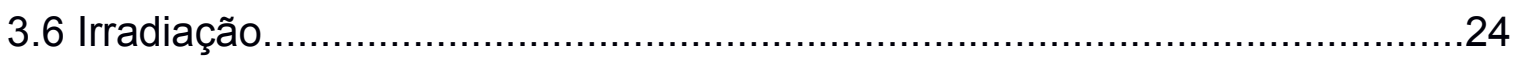

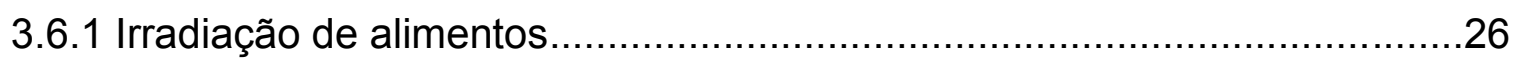

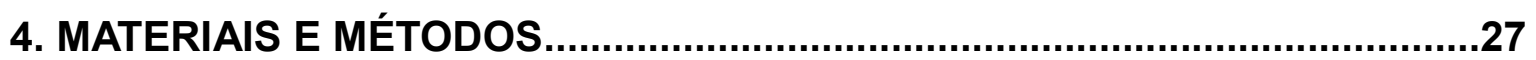

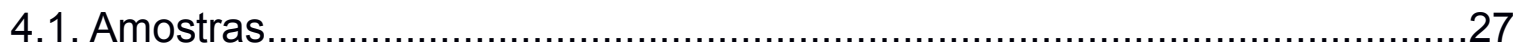

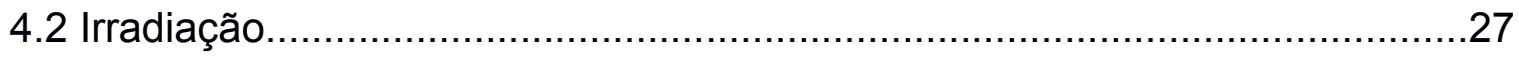

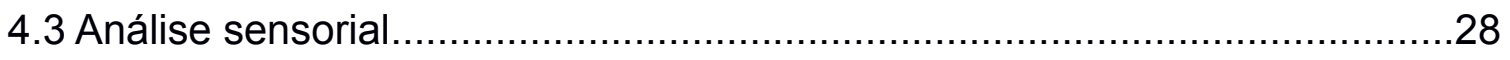

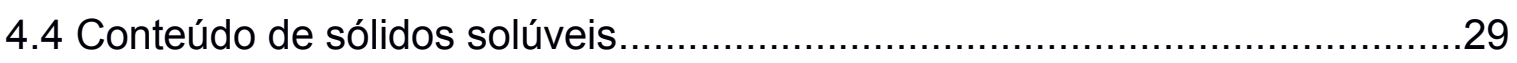

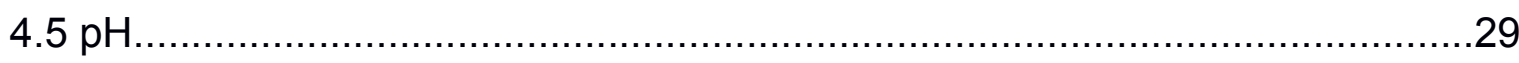

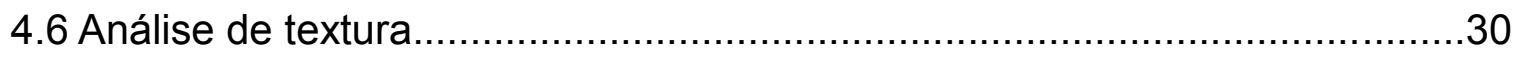

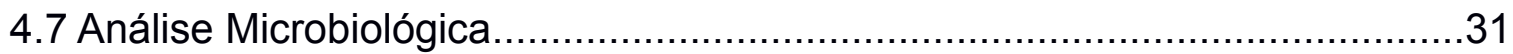

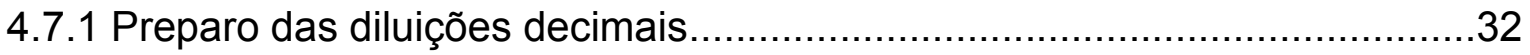

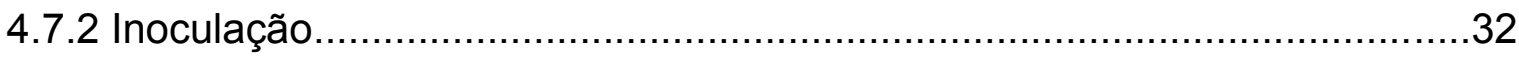

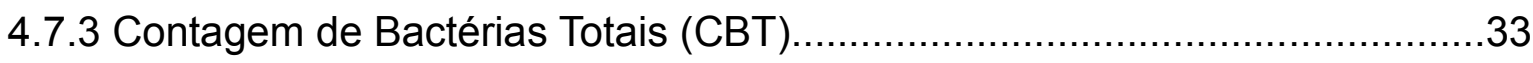

4.7.4 Coliformes totais e Escherichia coli........................................................33

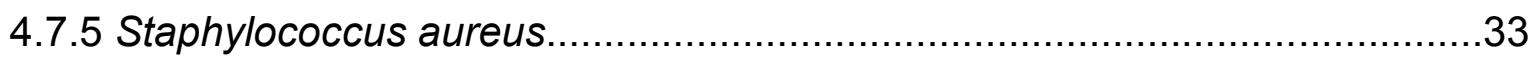

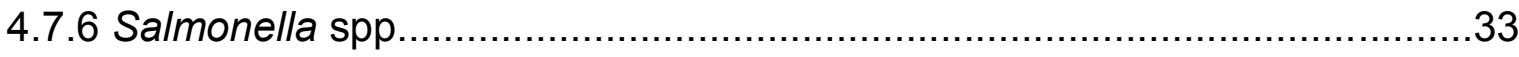


Página

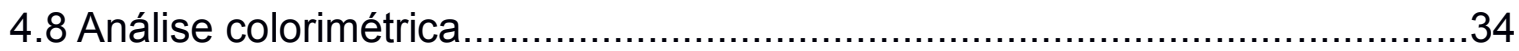

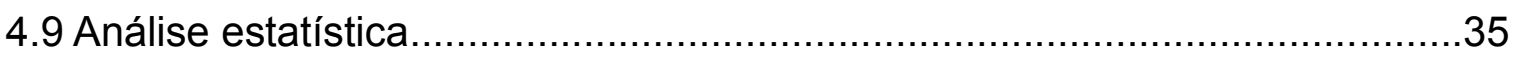

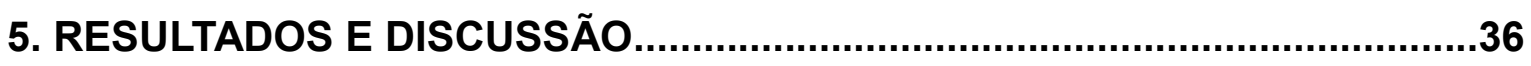

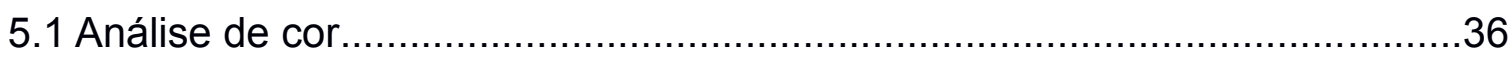

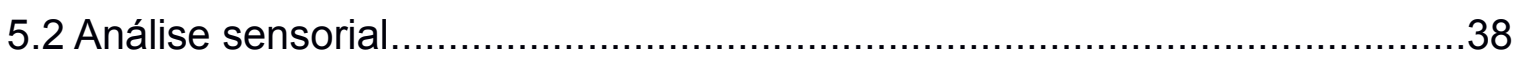

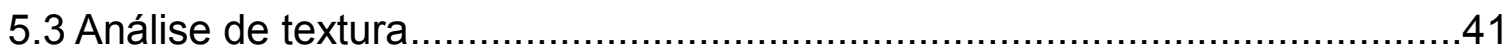

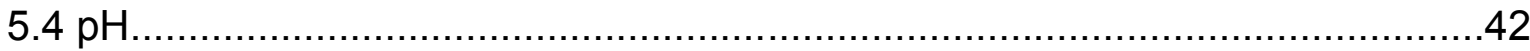

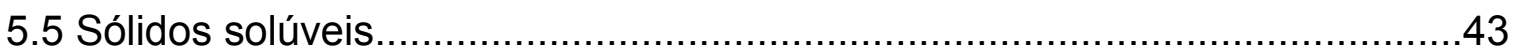

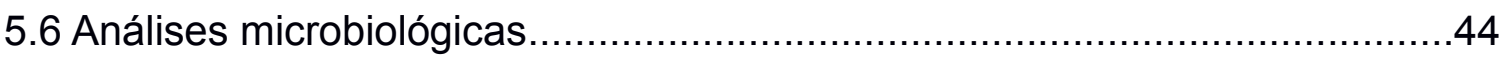

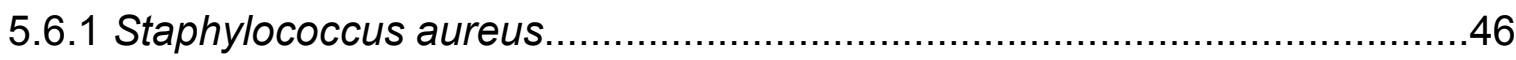

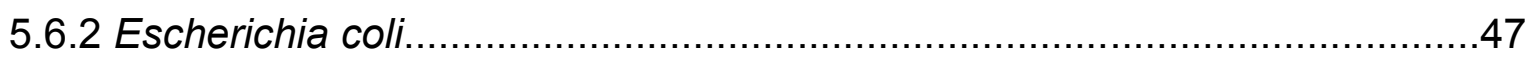

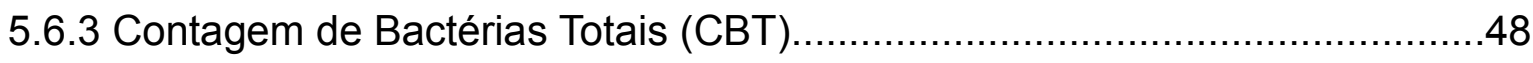

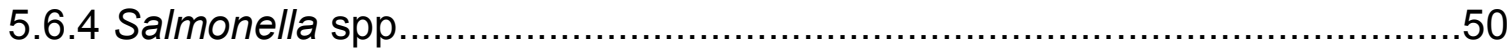

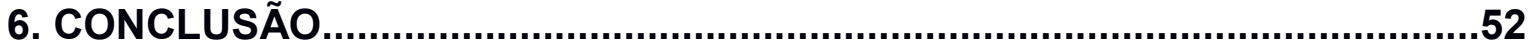

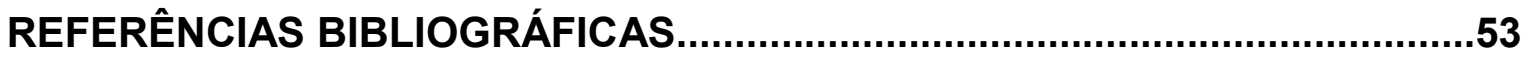




\section{LISTA DE TABELAS}

Página

Tabela 1. Padrões microbiológicos determinados pela RDC 12/01 para sorvetes .14

Tabela 2. Valores nutricionais médios calculados para do sorvete comparados com outros alimentos (Fonte ABIS, 2014)..... .20

Tabela 3. Caracterização de indivíduos neutropênicos (Fonte: Pattni e Hanlon, 2010)

Tabela 4. Alimentos proibidos para pacientes em dieta neutropênica (Fonte: Adaptado de Pattni e Hanlon, 2010).... 24

Tabela 5. Resultados da análise de cor dos sorvetes de creme irradiados. 37

Tabela 6. Média de pontos atribuídos às amostras de sorvete de creme irradiadas .39

Tabela 7. Resultados da análise sensorial de sorvete de creme light. 40

Tabela 8. Resultados de textura de sorvete de creme light, onde DV = desvio padrão. .42

Tabela 9. Valores de $\mathrm{pH}$ do sorvete de creme irradiado. 43 Tabela 10. Valores do teor de sólidos solúveis de sorvete de creme irradiado .44

Tabela 11. Resultados da análise microbiológica de sorvete de creme antes e após a irradiação .45

Tabela 12. Resultados de sorvete de creme light inoculado com S. aureus. .46

Tabela 13. Resultados de sorvete de creme light inoculado com E. coli. .47 Tabela 14. Resultados da Contagem de Bactérias Totais (CBT) em sorvete de creme light.

Tabela 15. Resultados de sorvete de creme light inoculado com Salmonella spp 


\section{LISTA DE FIGURAS}

Página

Figura 1. Consumo de sorvete no Brasil em milhões de litros (Fonte: ABIS, 2014) 16

Figura 2. Produção de sorvete no Brasil em milhões de litros (Fonte: ABIS, 2014) 17

Figura 3. Consumo per capita de sorvete no Brasil em litros/ano (Fonte: ABIS, 2014) 17

Figura 4. Comparação entre a produção de sorvete dos EUA, Brasil e Alemanha em 2011 (Fonte: Euroglaces, 2011).

Figura 5. Irradiador Multipropósito de ${ }^{60} \mathrm{Co}$ instalado no Centro de Tecnologia das Radiações (CTR) do IPEN-CNEN/USP (Fonte: O próprio autor, 2014). .28

Figura 6. Modelo de ficha de análise sensorial com escala hedônica de 9 pontos.

Figura 7. Texturômetro Stable Micro System modelo TA-TX Plus instalado no Centro de Tecnologia das Radiações (CTR) do IPEN-CNEN/USP (Fonte: O próprio autor, 2014).

Figura 8. Probe de pontos múltiplos utilizada no texturômetro Stable Micro System modelo TA-TX Plus (Fonte: O próprio autor, 2014). 31

Figura 9. Câmara asséptica instalada no Laboratório de Alimentos do Centro de Tecnologia das Radiações (CTR) do IPEN-CNEN/USP IPEN-CNEN/USP (Fonte: O próprio autor, 2014) 32

Figura 10. Colorímetro Minolta-Chromameter modelo CR400 instalado no Laboratório de Alimentos do Centro de Tecnologia das Radiações (CTR) do IPENCNEN/USP IPEN-CNEN/USP (Fonte: O próprio autor, 2014). 34

Figura 11. Resultado da análise colorimétrica de sorvete de creme light. 38

Figura 12. Grau de satisfação do sabor do sorvete de creme light. 41 


\section{INTRODUÇÃO}

A origem do sorvete pode estar relacionada a uma mistura de frutas e suco de frutas com neve, provavelmente, na China. O sorvete foi introduzido na Europa no final do século XIII, porém somente por volta de 1851, passou a ser produzido em grande quantidade, tornando-se um dos principais produtos das indústrias de produtos lácteos no mundo (VARNAM e SUTHERLAND, 1994; WARKE et al., 2000).

A composição do sorvete sofre variação dependendo da região onde é produzido. Essa variação é de aproximadamente 8 a 20\% de gorduras, 13 a 20\% de açúcares e 8 a 15\% de sólidos não gordurosos para sorvetes convencionais (ARBUCKLE, 1986).

Os sorvetes são alimentos produzidos a partir da emulsão de lipídios e proteínas, com adição ou não de açúcares e/ou outros ingredientes, sob agitação contínua e incorporação de ar, em condições tais que garantam a conservação do produto no estado congelado ou parcialmente congelado, durante a armazenagem, o transporte e a entrega ao consumo (ARBUCKLE, 1986; BORSZCZ, 2002; MATTHIAS et al., 2005).

Ao consumir alimentos, um dos problemas mais importantes está relacionado a doenças decorrentes de sua ingestão (RIBEIRO et al., 1999). Diversos surtos alimentares relacionados à contaminação microbiológica de sorvetes foram relatados nas últimas décadas em países da Ásia, Europa e América.

Acredita-se que o sorvete, por ser um alimento congelado, não apresenta riscos à saúde da população, porém, é considerado um excelente meio para o crescimento de microrganismos devido à sua composição, $\mathrm{pH}$ próximo a neutralidade (6 a 7) e longo período de armazenamento (CHUG, 1996; 
HENNESSY et al., 1996; DJURETIC et al., 1997; DODHIA et al., 1998; DANIELS et al., 2002; KANBAKNA et al., 2004; EL-SHAREF et al., 2006; JO et al., 2007).

Em 2013 foi relatado um surto, envolvendo a bactéria Staphylococcus aureus, em sorvetes produzidos e consumidos na Alemanha (FETSCH, 2014).

A irradiação de sorvetes tem a finalidade de assegurar a qualidade microbiológica, permitindo assim, que esse grupo de paciente possa usufruir desse alimento, que é rico em cálcio, proteínas, carboidratos e outros minerais, lipídios e vitaminas. A originalidade desse trabalho consiste principalmente no fato de que a irradiação de sorvete é pouco descrita na literatura, sendo necessário um estudo aprofundado na redução da carga microbiana para que o sorvete possa ser incluído na dieta de pacientes com sistema imunológico debilitado. Este trabalho é parte do projeto da IAEA - International Atomic Energy Agency: Application of ionizing radiation in foods for people with specifc diets (IAEA Research Contract 16226) presente no Coordinated Research Project: Irradiated foods for immunocompromised patients and other potential target groups (CRP D62009).

Esse trabalho visou obter dados sobre a segurança microbiológica de sorvetes, uma vez que esses produtos não são aconselháveis para pacientes imunocomprometidos, pois existe um risco em potencial desses pacientes serem acometidos por enfermidades oriundas desses alimentos. Durante seus tratamentos, os pacientes imunocomprometidos têm uma restrição alimentar muito grande, não podendo usufruir de alimentos frescos e derivados de produtos lácteos. Estas restrições prejudicam, assim, a absorção de nutrientes, além de causar danos na autoestima do paciente, principalmente crianças, que são os maiores consumidores de sorvete. 


\section{OBJETIVOS}

\subsection{Objetivo geral}

Avaliar os aspectos microbiológicos, sensoriais e físico-químicos de sorvetes de creme submetidos à irradiação.

\subsection{Objetivos específicos}

a. Determinar a dose mínima de radiação gama $\left({ }^{60} \mathrm{Co}\right)$ para garantir a redução de carga microbiana;

b. Determinar a dose máxima de radiação gama $\left({ }^{60} \mathrm{Co}\right)$ sem que ocorram alterações significativas em seus atributos físico-químicos e sensoriais;

c. Verificar as alterações físico-químicas no sorvete após a irradiação;

d. Avaliar os efeitos da radiação ionizante sobre microrganismos inoculados em amostras de sorvete. 


\section{REVISÃO DA LITERATURA}

\subsection{Sorvete}

\subsubsection{Definição de sorvete}

Segundo a Resolução RDC 266/05, o sorvete é definido como gelado comestível. Ele é um produto congelado, obtido a partir da emulsão de gorduras e proteínas ou de uma mistura de água e açúcar, podendo ser adicionados outros ingredientes desde que não descaracterizem o produto (BRASIL, 2005). Os gelados comestíveis devem seguir os padrões microbiológicos sanitários determinados pela Resolução RDC 12/01 (Tabela 1).

Tabela 1. Padrões microbiológicos determinados pela RDC 12/01 para sorvetes.

\begin{tabular}{cc}
\hline Microrganismo & Limite máximo \\
\hline Coliformes a $45^{\circ} \mathrm{C} / \mathrm{g}$ & $5 \times 10^{1}$ \\
Estafilococos coagulase positiva/g & $5 \times 10^{2}$ \\
Salmonella spp/25g & Ausente \\
\hline
\end{tabular}

A Resolução RDC 21/01 estabelece os requisitos gerais para o uso da irradiação de alimentos com vistas à qualidade sanitária do produto final. De acordo com essa legislação as fontes de radiação ionizantes permitidas são:
a. Cobalto 60;
b. Césio 137;
c. Raios X com energia de até $5,0 \mathrm{MeV}$;
d. Feixes de elétrons com energia de até $10 \mathrm{MeV}$. 
A RDC 21/01 ainda estabelece que a dose mínima absorvida deva ser suficiente para atingir o objetivo pretendido e a máxima inferior àquela que comprometeria as propriedades funcionais e/ou atributos sensoriais do alimento.

\subsubsection{Composição básica de sorvete}

O sorvete a base de leite é constituído de uma suspensão aerada de gordura e cristais de gelo, em uma solução de açúcar concentrado contendo hidrocolóides, gorduras, proteínas e outros ingredientes. A composição do sorvete pode variar de uma região à outra (OLIVEIRA, 2008). As gorduras podem variar de 8 a 20\%, os sólidos não gordurosos do leite variam de 8 a 15\% e o açúcar varia de 13 a $20 \%$ (ARBUCKLE, 1986).

O sorvete é considerado um alimento de alto valor nutricional, fornecendo lipídios, carboidratos, proteínas, cálcio, fósforo, minerais e vitaminas $A, B 1, B 2$, B6, C, D, E e K (ARBUCKLE, 1986; MAIA et al., 2008).

\subsubsection{Dados mercadológicos}

O sorvete é o produto mais importante e de maior interesse para as indústrias de produtos lácteos devido à grande demanda pela população (MANN, 1988; WARKE et al., 2000). Somente nos Estados Unidos da América, no ano de 2004, mais de seis milhões de litros de sorvete foram produzidos e as exportações alcançaram 41 milhões de litros (GOFF, 2008).

De acordo com a Associação Brasileira da Indústria de Sorvetes, o Brasil apresentou um crescimento de $81,6 \%$ no consumo de sorvete no período de 2003 a 2013, variando de 685 milhões de litros para 1244 milhões de litros anuais mostrado na Figura 1(ABIS, 2014). 


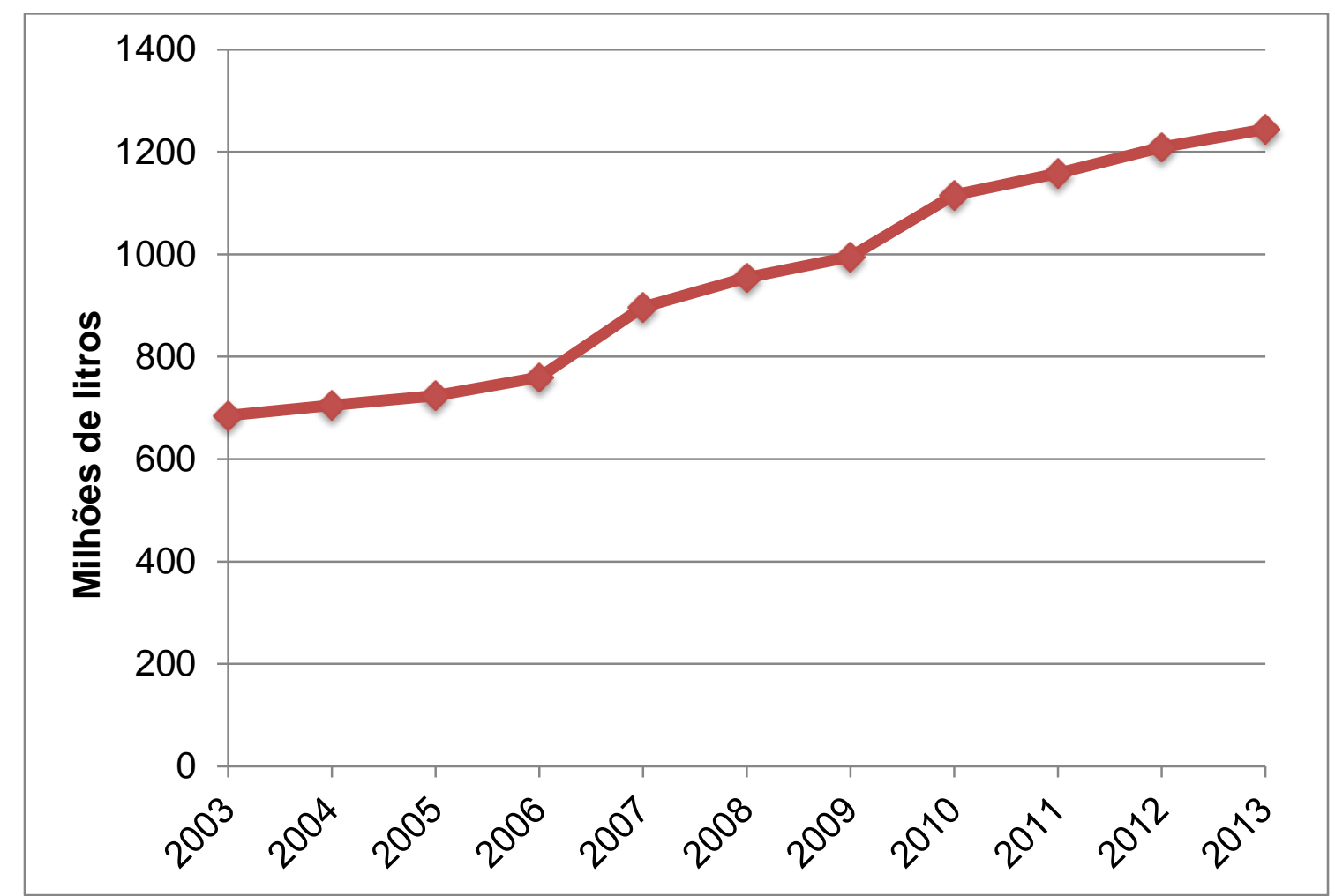

Figura 1. Consumo de sorvete no Brasil em milhões de litros (Fonte: ABIS, 2014).

Na última década a produção de sorvete de massa aumentou de 502 milhões de litros, em 2003, para 885 milhões de litros em 2013 (Figura 2); já o consumo per capita variou de 3,83 litros/ano para 6,19 litros por ano, mostrado na Figura 3 (ABIS, 2014). 


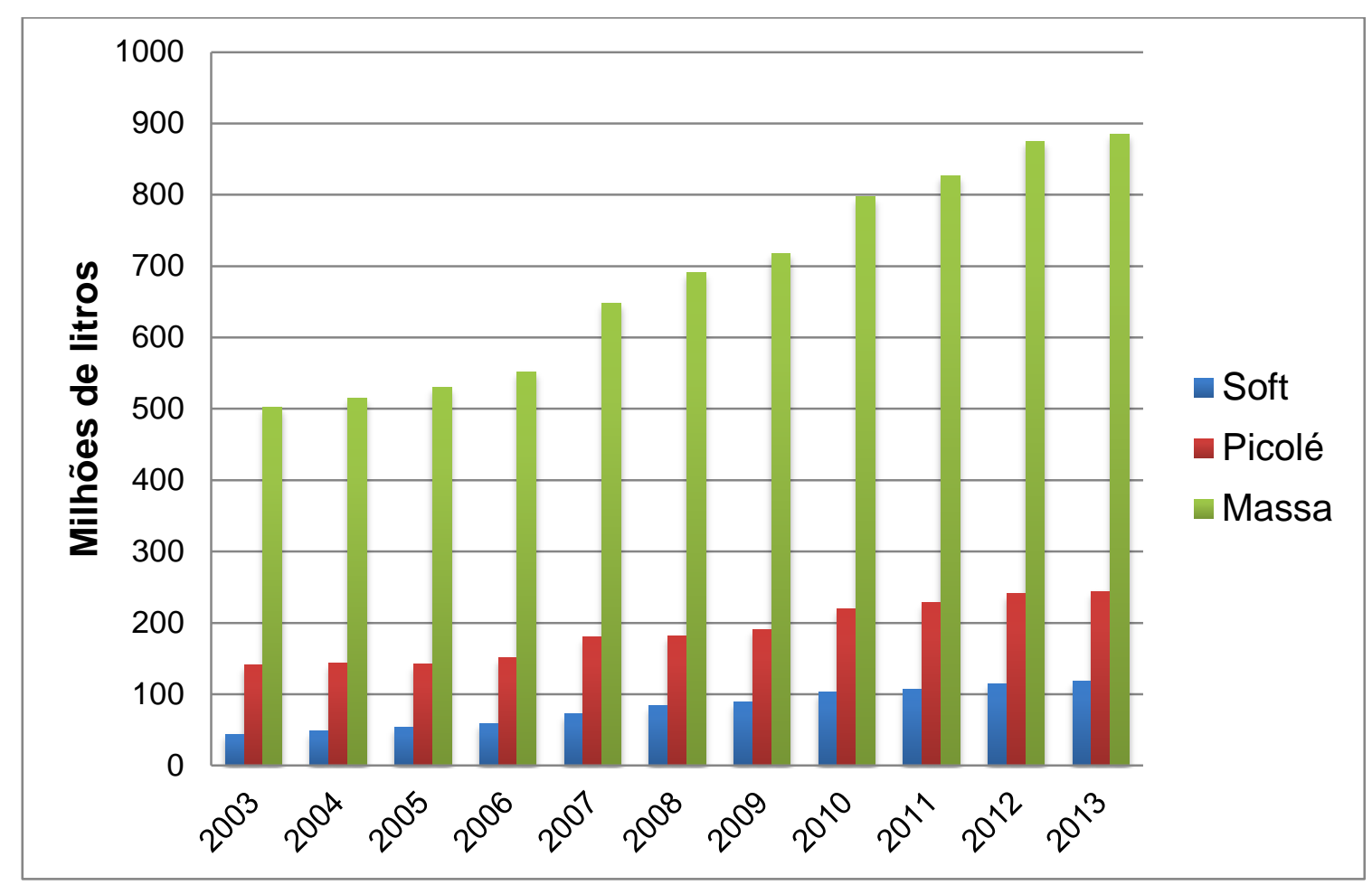

Figura 2. Produção de sorvete no Brasil em milhões de litros (Fonte: ABIS, 2014).

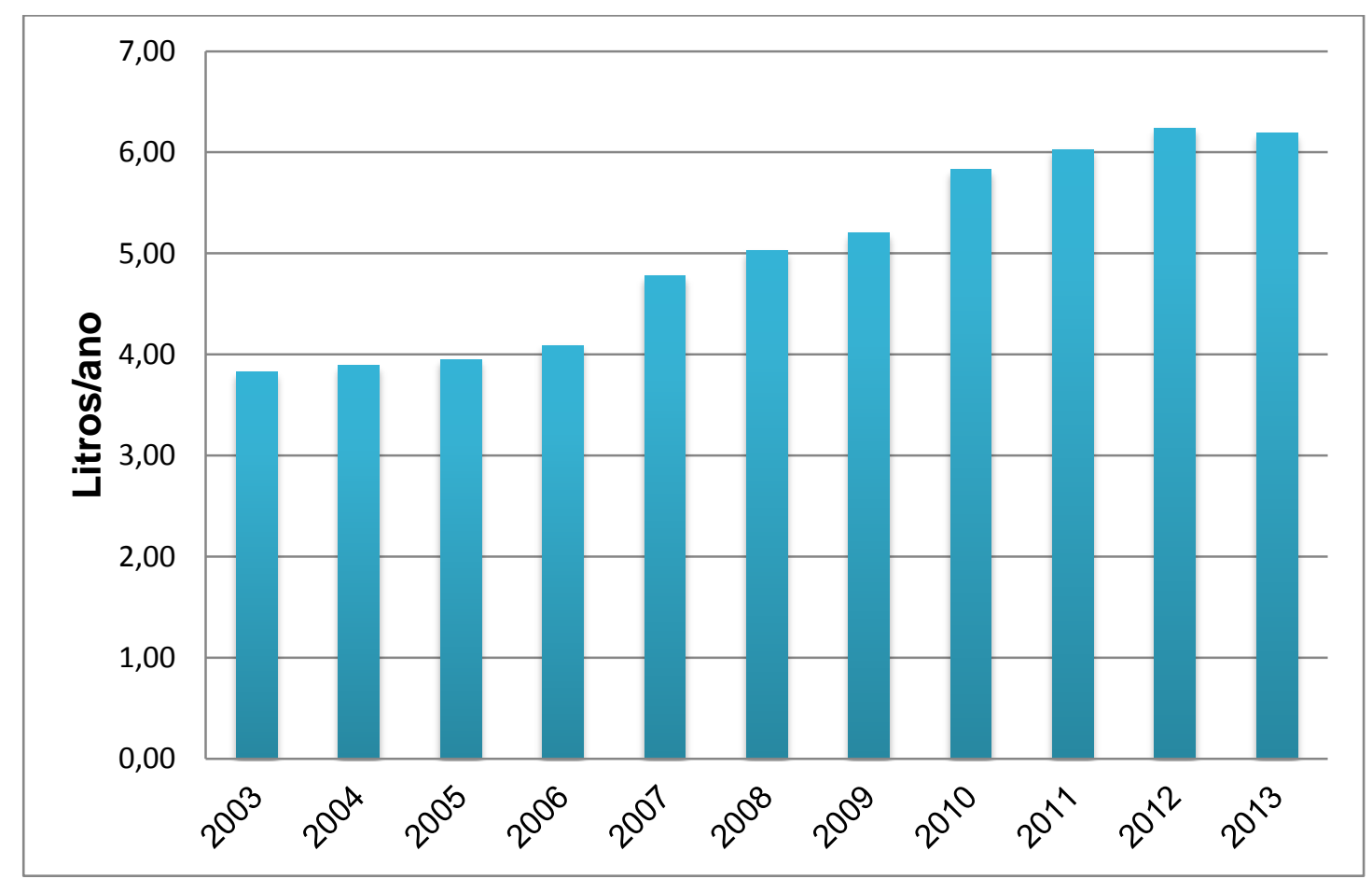

Figura 3. Consumo per capita de sorvete no Brasil em litros/ano (Fonte: ABIS, 2014). 
Nos EUA foram produzidos aproximadamente 5,8 bilhões de litros de sobremesa congelada em 2011. Somente a região central desse país, fabricou cerca de 2750 milhões de litros de sorvete. Em 2010, a indústria de sorvete norte americana gerou uma receita de 10 bilhões de dólares (IDFA, 2014).

O país europeu líder em produção de sorvete no ano de 2011 foi a Alemanha, com aproximadamente 590 milhões de litros, seguido de França e Itália, com 446 e 431 milhões de litros, respectivamente. Comparando-se a produção do ano de 2011 (Figura 4), os EUA produziram praticamente duas vezes mais que Brasil e Alemanha juntos (ABIS, 2014; EUROGLACES, 2014).

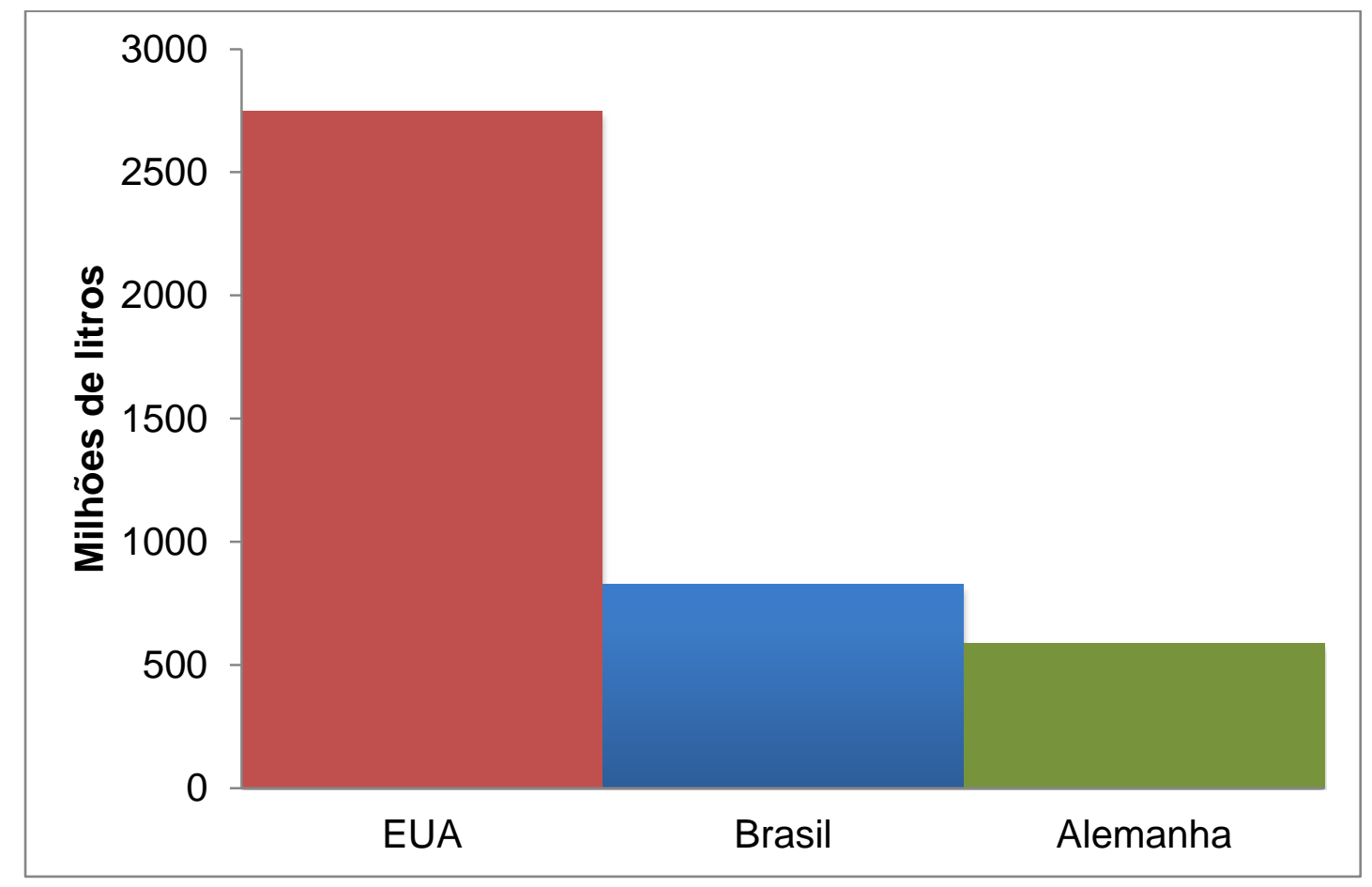

Figura 4. Comparação entre a produção de sorvete dos EUA, Brasil e Alemanha em 2011 (Fonte: Euroglaces, 2011). 


\subsubsection{Características microbiológicas de sorvete}

A contaminação de sorvetes por microrganismos patogênicos durante a produção ocasionou diversos surtos em vários países na Ásia, Europa e América (CHUG, 1996; HENNESSY et al., 1996; DJURECT et al., 1997; DODHIA et al., 1998; DANIELS et al., 2002; EL-SHAREF et al., 2006). Isso acontece, pois o sorvete é um excelente meio para crescimento microbiológico devido à sua composição, $\mathrm{pH}$ geralmente neutro (6 a 7) e longo período de armazenamento (KANBAKNA et al., 2004; JO et al., 2007).

Durante o período de 1973 até 1977, diversos surtos alimentares em escolas dos Estados Unidos foram associados ao consumo de sorvete (DANIELS et al., 2002). Na Turquia, $25 \%$ dos sorvetes comercializados apresentaram contagem total de bactérias acima dos limites seguros estabelecido pelos padrões turcos (KANBAKNA et al., 2004).

A incidência de microrganismos patogênicos como, por exemplo, Listeria monocytogenes, Salmonella spp, Yersinia enterocolitica e Bacillus cereus, em leite e seus derivados, tem sido associada a doenças de origem alimentares em diversos países, inclusive países como os Estados Unidos e Inglaterra (AHAMED et al., 1983; ANON, 1986; PALUMBO, 1986; WHO, 1988; de CENTORBI et al., 1989; KAMAT et al., 1989; ANON, 1990a, b; GREENWOOD et al., 1991; SALEH et al., 1993; CHAMPAGNE et al., 1994; ANON, 1997; PEDNEKAR et al., 1997).

Warke et al. (2000) relataram que o nível de coliformes em sorvetes na Índia foi de 10 a 100 vezes maior que o limite estabelecido pelo "Indian Standards Institute" (ISI) bem como relataram a presença de Staphylococcus aureus em todas as amostras de sorvete analisadas. 


\subsubsection{Aspectos nutricionais de sorvete}

Na Tabela 2 podem-se observar os valores de carboidratos, proteínas, lipídios e a quantidade de calorias de sorvete de creme e sorvete de creme light em comparação com outros alimentos (ABIS, 2014).

Tabela 2. Valores nutricionais médios calculados para do sorvete comparados com outros alimentos (Fonte ABIS, 2014).

\begin{tabular}{ccccc}
\hline Alimento (100g) & $\begin{array}{c}\text { Calorias } \\
(\mathbf{k c a l})\end{array}$ & $\begin{array}{c}\text { Carboidratos } \\
\mathbf{( g )}\end{array}$ & $\begin{array}{c}\text { Proteínas } \\
\mathbf{( g )}\end{array}$ & Gorduras $(\mathbf{g})$ \\
\hline $\begin{array}{c}\text { Sorvete de creme } \\
\text { (base leite) }\end{array}$ & 100 & 26,6 & 2,83 & 6 \\
$\begin{array}{c}\text { Sorvete de creme } \\
\text { light (base leite) }\end{array}$ & 100 & 18,33 & 3,33 & 1,83 \\
Sorvete (base água) & 126,3 & 30 & 1,5 & $*$ \\
Carne bovina assada & 287,7 & 0 & 25,25 & 20,75 \\
Arroz cozido & 109,7 & 24,4 & 2,8 & 0,1 \\
Pão francês & 269 & 57,4 & 9,3 & 0,2 \\
Leite em pó & 351 & 49,5 & 35,5 & 0,8 \\
desnatado & & 57,4 & 3,8 & 17,2 \\
Ovo frito & 216 & & & \\
\hline
\end{tabular}

\subsection{Textura}

A textura é um atributo físico de grande importância, pois, está relacionada ao processo mastigatório e satisfação por parte do consumidor. A textura é definida de acordo com o estado físico dos alimentos. A nomenclatura para alimentos líquidos homogêneos é "viscosidade"; para alimentos semissólidos é "firmeza" e para alimentos sólidos é "textura" (DUTCOSKY, 2007). 
A percepção do alimento na cavidade oral está relacionada aos órgãos localizados na superfície da boca (palato e língua) (FARIA e YOTSUYANAGI, 2002). A qualidade do sorvete leva em consideração a textura, que é a sensação de frescor percebida pelos consumidores (CHANG e HARTEL, 2002).

A textura é utilizada como padrão de aceitabilidade pelo consumidor e processadores de alimentos, sendo importante a compreensão da textura para controlar o processo de fabricação para obter um produto de qualidade, podendo utilizar análises sensoriais e instrumentais (CHEN e OPARA, 2013).

\subsection{Cor}

A cor é percebida através de fatores físicos e fisiológicos, pelos quais o comprimento de onda de luz é percebido pelo olho. Na retina localizam-se os cones e bastonetes, onde ocorre a detecção de cor e visualização de formas e luz escura, respectivamente.

De acordo com os aspectos visuais dos alimentos o consumidor tende a esperar certas características, pois o sentido da visão dá informação sobre o aspecto de um alimento: estado, tamanho, forma, textura e cor antecipando-se na recepção das outras informações, podendo produzir uma resposta forte, julgando o frescor, assim como tornando o produto apetitoso, como, por exemplo, a coloração de um sorvete (FARIA e YOTSUYANAGI, 2002; DUTCOSKY, 2007).

\subsection{Análise Sensorial}

A análise sensorial é uma ciência interdisciplinar na qual avaliadores são convidados e utilizando-se da interação dos sentidos (visão, gosto, tato e audição) poderão avaliar as características sensoriais e aceitabilidade do produto (WATTS et al., 1989). Essa ciência vem sendo utilizada no desenvolvimento e melhoramento de produtos, estudos sobre armazenamento, controle de qualidade e desenvolvimento de processos (MORAES, 2000).

Para análises de aceitação do consumidor necessita-se de um grande 
número de provadores não treinados e não selecionados, sendo necessário que eles sejam consumidores do produto testado (CHAVES e SPROESSER, 1993).

Durante provas sensoriais os avaliadores podem sofrer influencia externa resultando em aspectos psicológicos produzindo falsos resultados. Os erros mais comuns que podem ser provocados por interferentes são de (LANZILLOTT e LANZILLOTT, 1999):

a. Expectativas: avaliadores recebem informações em demasia sobre o experimento como, por exemplo, muitos tipos de amostras;

b. Estimulação: avaliadores recebem amostras heterogêneas como, por exemplo, diferença na cor, forma e tamanho dos produtos apresentados;

c. Contraste: avaliadores recebem amostras contrastantes como, por exemplo, amostras agradáveis seguidas de amostras desagradáveis.

A análise sensorial é uma tomada de decisão, sendo necessário avaliar as possibilidades de inserção de um produto no cotidiano do consumidor e seu objetivo é mensurar o nível de prazer ou desprazer utilizando-se da escala hedônica (LANZILLOTT e LANZILLOTT, 1999).

\subsection{Imunocomprometidos}

Pacientes imunocomprometidos são pessoas que apresentam uma deficiência em seu mecanismo de defesa, tais como portadores de HIV, pacientes em tratamento contra o câncer e transplantados. Recém-nascidos, gestantes e idosos portadores de alguma enfermidade também são considerados imunocomprometidos (FELICIANO et al., 2014).

Os pacientes em tratamento contra o câncer apresentam uma baixa contagem de neutrófilos, que são a primeira linha de defesa do corpo humano. Neutropenia é a designação utilizada quando a contagem de neutrófilo está abaixo de $1,5 \times 10^{9}$ por litro de sangue (Tabela 3 ). 
Tabela 3. Caracterização de indivíduos neutropênicos (Fonte: Pattni e Hanlon, 2010).

\begin{tabular}{ccc}
\hline Definição & Contagem de neutrófilo & Paciente \\
\hline Normal & $>1,5 \times 10^{9} / \mathrm{L}$ & População normal \\
Neutropenia nível 1 & $>0,5 \times 10^{9} / \mathrm{L}$ & Quimioterapia \\
Leucemia aguda, \\
Neutropenia profunda & $<0,5 \times 10^{9} / \mathrm{L}$ & transplante de medula \\
& & óssea \\
\hline
\end{tabular}

A dieta neutropênica vem sendo utilizada desde a década de 1960 em pacientes imunocomprometidos visando reduzir a ingestão de patógenos provenientes dos alimentos. Os pacientes neutropênicos estão em risco constante de infecção. Primeiro, porque estão com o sistema imunológico comprometido em função de uma leucemia, quimioterapia, devido a um transplante. Segundo, porque a translocação bacteriana do intestino para o linfonodo, corrente sanguínea, fígado e baço são mais recorrentes nesta população (PATTNI e HANLON, 2010).

A dieta neutropênica deve ser seguida por prazo indeterminado, até que o paciente restabeleça a contagem normal de neutrófilos. Esta dieta é imposta aos pacientes, havendo grande restrição de alimentos que podem ser ingeridos, como por exemplo, frutas e vegetais crus, ovos, produtos lácteos não pasteurizados, carnes mal passadas dentre outros (Tabela 4). 
Tabela 4. Alimentos proibidos para pacientes em dieta neutropênica (Fonte: Adaptado de Pattni e Hanlon, 2010).

\begin{tabular}{|c|c|}
\hline Grupo de alimentos & Exemplos de alimentos \\
\hline Vegetais crus & $\begin{array}{l}\text { Vegetal com casca, saladas prontas para } \\
\text { consumo, saladas cruas, tomates crus, } \\
\text { alface, aipo, espinafre não cozido }\end{array}$ \\
\hline Frutas & $\begin{array}{c}\text { Frutas com casca (maçã) } \\
\text { Frutas macias, morango, framboesa, } \\
\text { amora }\end{array}$ \\
\hline Frutas secas & Uva passa, damasco \\
\hline Ovos & $\begin{array}{c}\text { Ovo cru ou mal passado, maionese } \\
\text { caseira }\end{array}$ \\
\hline Carnes & Carne crua ou mal passada \\
\hline Castanhas & Castanhas, amendoim, nozes \\
\hline Temperos não cozidos & Pimenta, orégano \\
\hline Leite & $\begin{array}{l}\text { Leite não pasteurizado, sorvete de } \\
\text { máquina, iogurte não pasteurizado, } \\
\text { produtos probióticos }\end{array}$ \\
\hline $\begin{array}{l}\text { Queijos não pasteurizados (queijos Azuis } \\
\text { e macios) }\end{array}$ & $\begin{array}{l}\text { Brie, Camembert, Roquefort, queijos de } \\
\text { cabra }\end{array}$ \\
\hline
\end{tabular}

\subsection{Irradiação}

A radiação é um fenômeno físico, onde ocorre a emissão e propagação de energia através do espaço ou de uma matéria (RADOMYSKI et al., 1994). O termo radiação é utilizado para designar processos físicos de emissão e propagação de energia, seja por intermédio de fenômenos ondulatórios, seja por meio de partículas dotadas de energia cinética (FDA, 1985; USDA, 1985; FDA, 1994; FDA, 1997; AQUINO, 2003). 
A irradiação é o processo de aplicação desta energia a um material, com a finalidade de reduzir carga microbiana através da destruição de microrganismos, parasitas, insetos e outras pragas. O tipo de radiação usada é a chamada ionizante, pois ela produz partículas eletricamente modificadas (íons) por efeito Compton. A grande diferença entre os raios gama provenientes de uma fonte de ${ }^{60} \mathrm{Co}$ e o feixe de elétrons oriundo de um acelerador industrial, é o seu poder de penetração (DIEHL, 1995).

A radiação gama tem um alto poder de penetração. No entanto, possui menor taxa de dose quando comparada ao feixe de elétrons gerado por um acelerador, o qual, por sua vez, tem um poder de penetração menor, mas alta taxa de dose de radiação (DIEHL, 1995). A unidade utilizada para dose absorvida denomina-se Gray (Gy), onde 1,0Gy é equivalente à energia de 1,0 Joule absorvido por $1,0 \mathrm{~kg}$ de material (SATIN, 1993).

As radiações ionizantes podem modificar características físicas, químicas e propriedades biológicas dos materiais irradiados. Atualmente, as principais aplicações industriais da radiação são esterilização dos produtos de saúde, incluindo produtos farmacêuticos, irradiação de alimentos e produtos agrícolas (para vários objetivos finais, tais como desinfestação, aumento da vida de prateleira, inibição do brotamento, controle de pragas e redução de carga microbiana) e modificação de materiais (IAEA, 2005).

Um impulso significativo foi dado à indústria de processamento por radiação com $\mathrm{o}$ advento dos reatores nucleares de potência, que têm a capacidade de produzir radioisótopos. Emissor de raios gama, como o ${ }^{60} \mathrm{Co}$, tornou-se popular para aplicações médicas e industriais. Muitos irradiadores de raios gama foram construídos e estima-se que cerca de 200 estão em funcionamento atualmente nos Estados Membros da Agência Internacional de Energia Atômica (AIEA). Nos últimos anos, o uso de aceleradores de elétrons como uma fonte de radiação (e por vezes equipados com conversor de raios $\mathrm{X}$ ) está aumentando (IAEA, 2005).

No entanto, os irradiadores gama são difíceis de substituir, 
especialmente para produtos não uniformes e de alta densidade. $\mathrm{O}{ }^{60} \mathrm{Co}$ é utilizado quase exclusivamente como o fonte de radiação gama para uso industrial, principalmente devido a seu fácil método de produção e a sua não solubilidade em água (IAEA, 2005).

\subsubsection{Irradiação de alimentos}

A irradiação tem diversas vantagens em relação a outros métodos de tratamentos, como por exemplo, esterilização de produtos de saúde utilizando-se óxido de etileno e calor. No caso da esterilização por raios gama, tais vantagens incluem: os produtos tratados podem ser utilizados imediatamente; o aumento da temperatura do produto é mínimo durante o processamento por radiação; elevada penetrabilidade (o produto pode ser processado na sua embalagem final) (FARKAS, 2006). 


\section{MATERIAIS E MÉTODOS}

\subsection{Amostras}

Foram compradas 15 amostras de sorvete de creme e 12 amostras de sorvete de creme com teor reduzido de gordura (light) de uma indústria de grande porte no mercado varejista do Município de São Paulo.

\subsection{Irradiação}

As amostras de sorvete de creme e sorvete de creme light foram irradiadas no Irradiador Multipropósito de ${ }^{60} \mathrm{Co}$ localizado no IPEN-CNEN/SP (Figura 5). O sorvete de creme foi dividido em dois grupos, um acondicionado na embalagem plástica original e o outro foi irradiado em uma embalagem de vidro para verificar se o sabor do sorvete sofria influência da embalagem original. Para a irradiação, o sorvete foi transferido da embalagem original para a embalagem de vidro com o auxílio de uma espátula. As doses aplicadas, baseadas em trabalhos descritos na literatura, foram de 3,0kGy e 5,0kGy com taxa de dose de 4,5 kGy/h. Para as análises microbiológicas as doses foram de 1,0kGy, 2,0kGy, 3,0kGy e 4,0kGy. As amostras de sorvete de creme light foram irradiadas com doses de 1,0kGy e $2,0 \mathrm{kG}$ a temperatura de $-72^{\circ} \mathrm{C}$.

Para as amostras de sorvete de creme light destinadas as análises microbiológicas as doses utilizadas foram de 1,0kGy, 2,0kGy e 3,0kGy. Dosímetros Amber 3042 Batch S 603nm e Gammachrome YR Batch 5 (530nm) foram utilizados para mensurar a dose absorvida nas amostras de sorvete de creme. 


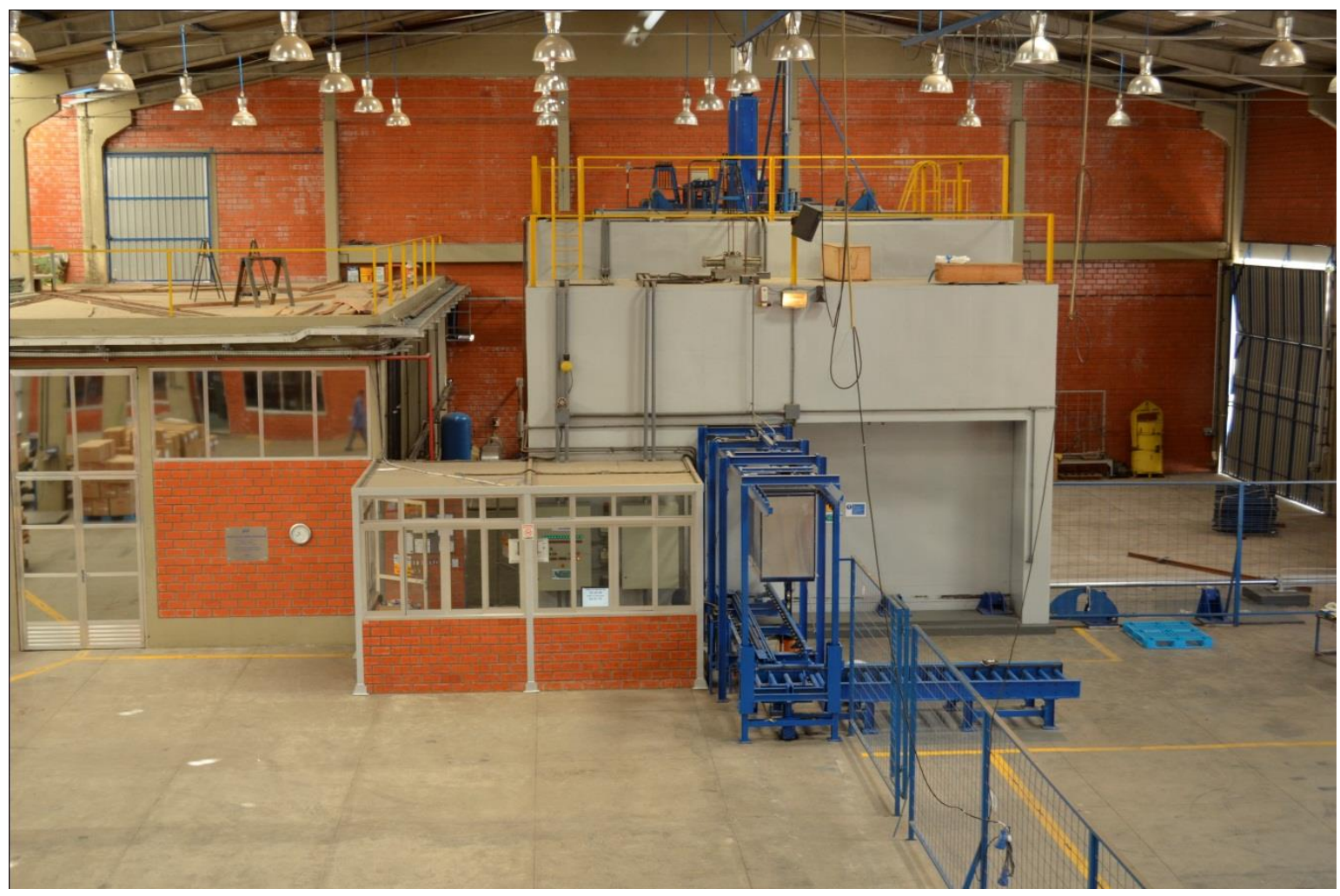

Figura 5. Irradiador Multipropósito de ${ }^{60} \mathrm{Co}$ instalado no Centro de Tecnologia das Radiações (CTR) do IPEN-CNEN/USP (Fonte: O próprio autor, 2014).

\subsection{Análise sensorial}

A análise sensorial do sorvete de creme foi conduzida com 50 painelistas não treinados oriundos do próprio Instituto, sendo aplicado o Teste Afetivo de Aceitação com o auxílio de uma escala hedônica de 9 pontos (Figura 6). A nota de corte foi de 6 pontos. Os painelistas analisaram aspectos como cor, textura, sabor e aparência global (DUTCOSKY, 2007). A análise sensorial do sorvete de creme light foi conduzida com 30 painelistas não treinados do próprio Instituto que analisaram aspectos de cor e sabor. 
NOME IDADE

Beba um gole de água e avalie a amostra usando a escala abaixo para descrever o quanto gostou ou desgostou do produto.

\begin{tabular}{|l|l|l|}
\hline \multicolumn{2}{|c|}{ Cor } & \multicolumn{2}{c|}{ Sabor } \\
\hline & 9-gostei muitíssimo & 9-gostei muitíssimo \\
\hline & 8-gostei muito & 8-gostei muito \\
\hline & 7-gostei regularmente & 7-gostei regularmente \\
\hline & 6-gostei ligeiramente & 6-gostei ligeiramente \\
\hline & 5-indiferente & 5-indiferente \\
\hline & 4-desgostei ligeiramente & 4-desgostei ligeiramente \\
\hline & 3-desgostei regularmente & 3-desgostei regularmente \\
\hline & 2-desgostei muito & 2-desgostei muito \\
\hline & 1-desgostei muitíssimo & 1-desgostei muitíssimo \\
\hline
\end{tabular}

Figura 6. Modelo de ficha de análise sensorial com escala hedônica de 9 pontos.

\subsection{Conteúdo de sólidos solúveis}

O teor de sólido solúvel do sorvete de creme ( ${ }^{\circ}$ Brix) foi determinado com um refratômetro $A B B E$ (modelo Q-767b), segundo AOAC (1995).

\section{$4.5 \mathrm{pH}$}

$\mathrm{O}$ valor de $\mathrm{pH}$ das amostras de sorvete de creme foi determinado usando um pHmetro Micronal (modelo B474), segundo AOAC (1995). 


\subsection{Análise de textura}

A análise de textura foi realizada com o auxílio de um texturômetro Stable Micro System modelo TA-TX Plus (Figura 7) equipado com célula de carga de $50 \mathrm{~kg}$ e uma Probe de pontos múltiplos (Figura 8 ) a $10^{\circ} \mathrm{C}$ e velocidade de descida de $1,0 \mathrm{~mm} / \mathrm{s}$ (BOURNE, 1978).

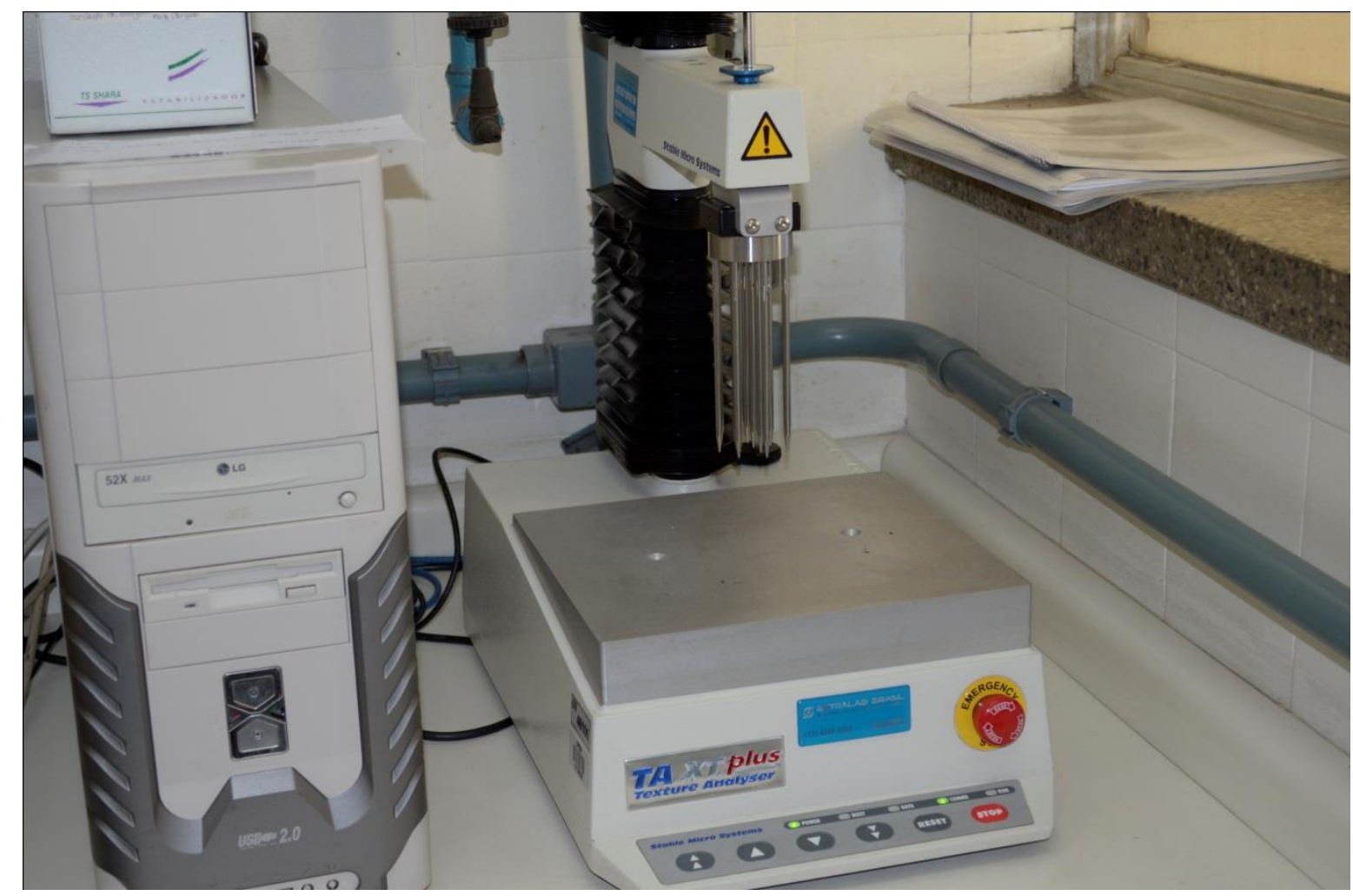

Figura 7. Texturômetro Stable Micro System modelo TA-TX Plus instalado no Centro de Tecnologia das Radiações (CTR) do IPEN-CNEN/USP (Fonte: O próprio autor, 2014). 


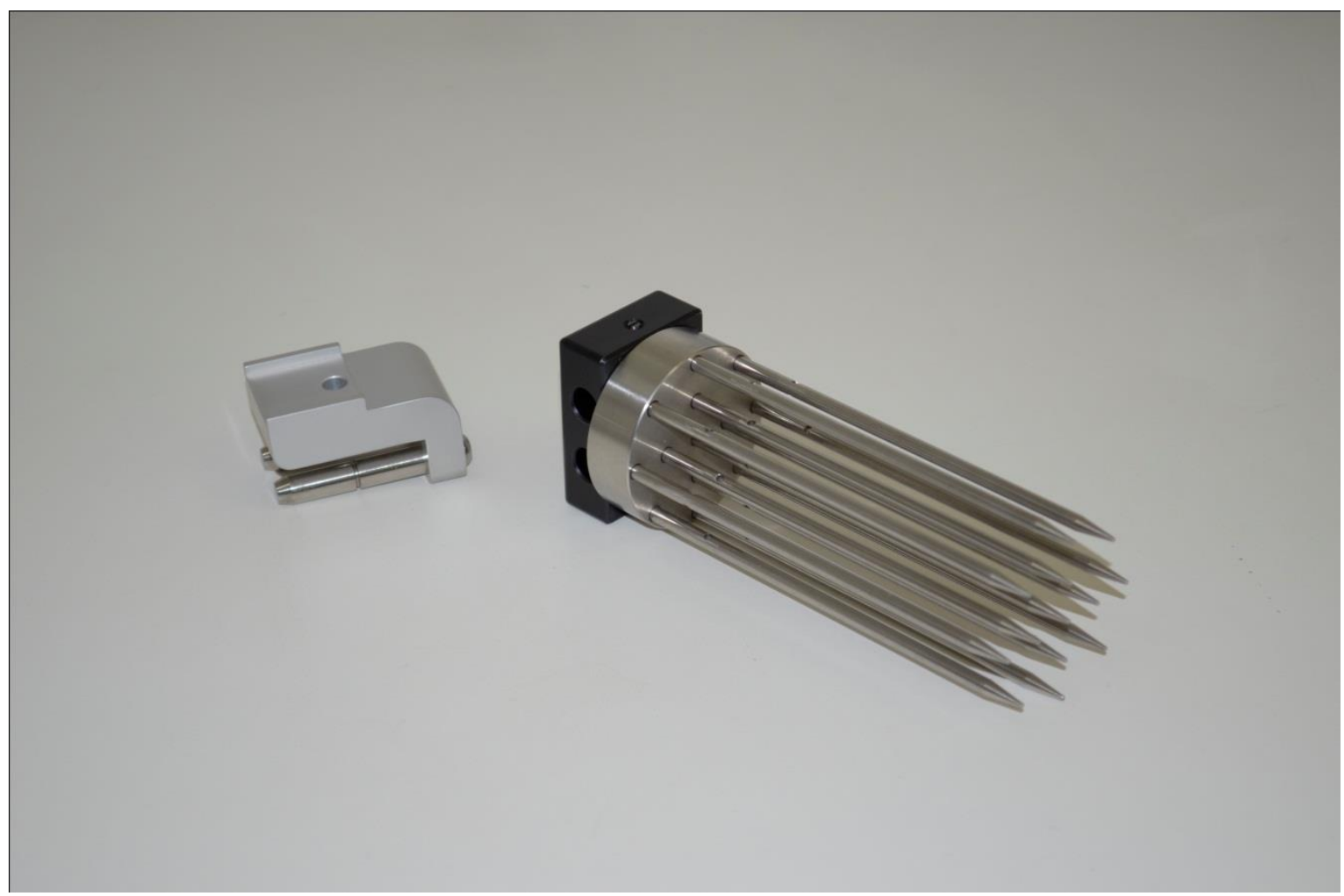

Figura 8. Probe de pontos múltiplos utilizada no texturômetro Stable Micro System modelo TA-TX Plus (Fonte: O próprio autor, 2014).

\subsection{Análise Microbiológica}

As análises microbiológicas do sorvete de creme foram realizadas de acordo com a metodologia $3 \mathrm{M}^{\mathrm{TM}}$ Petrifilm ${ }^{\mathrm{TM}}$ (Figura 9) recomendada pela AOAC (2002). 


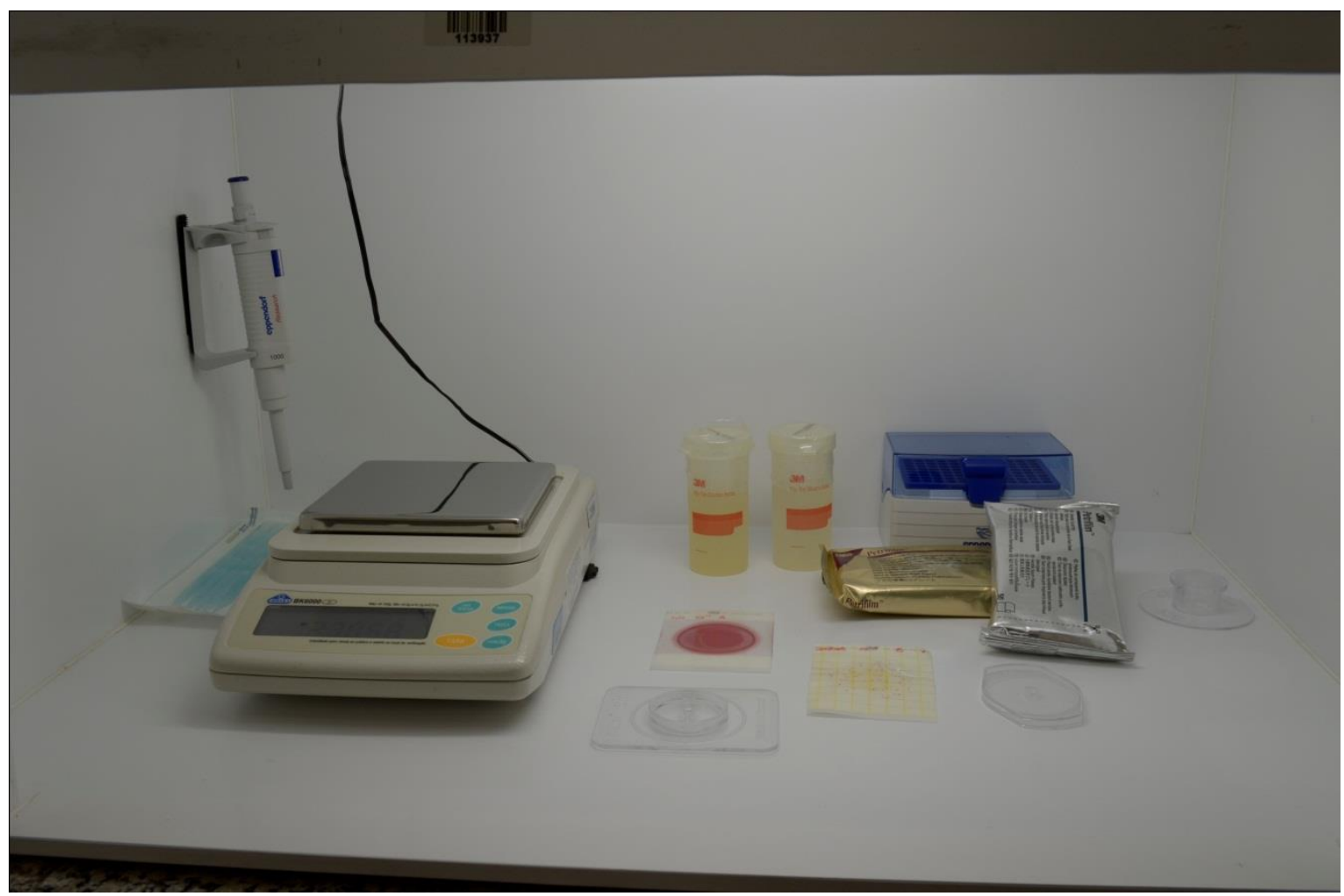

Figura 9. Câmara asséptica instalada no Laboratório de Alimentos do Centro de Tecnologia das Radiações (CTR) do IPEN-CNEN/USP IPEN-CNEN/USP (Fonte: O próprio autor, 2014).

\subsubsection{Preparo das diluições decimais}

As amostras de sorvete de creme foram fracionadas em porções de $10 \mathrm{~g}$ e homogeneizadas, sob agitação, com $90 \mathrm{~mL}$ de água peptonada $0,1 \%$ durante 1,0 minuto e, a partir desta suspensão foram preparadas as diluições decimais seriadas $(1: 10)$ em duplicata até $10^{-6}$ com água peptonada $0,1 \%$ (BAM/FDA, 2003).

\subsubsection{Inoculação}

Nove amostras de sorvetes de creme light destinadas a inoculação foram adicionadas de 1,0mL das cepas de Escherichia coli (ATCC 11229) e cepas de Staphylococcus aureus (ATCC 6538) numa concentração de $10^{8}$ UFC/g e 1,0mL 
de Salmonella abaetetuba (ATCC 35640) numa concentração de $10^{6}$ UFC/g. O volume de cada suspensão de inóculo foi transferido visando obter uma concentração de $10^{6}$ UFC/g (APHA, 2001).

\subsubsection{Contagem de Bactérias Totais (CBT)}

A contagem total de bactérias aeróbias mesófilas no sorvete de creme foi realizada em Petrifilm ${ }^{\mathrm{TM}} 3 \mathrm{M}^{\mathrm{TM}}$ Aerobic Count (AC). As amostras foram incubadas por $48 \pm 3 \mathrm{~h}$ a $32 \pm 1^{\circ} \mathrm{C}$, Segundo o método AOAC (2002). Para o sorvete de creme light a contagem de bactérias totais aeróbias mesófilas foi realizada após incubação de $48 \pm 3 \mathrm{~h}$ a $32 \pm 1^{\circ} \mathrm{C}$ (APHA, 2001).

\subsubsection{Coliformes totais e Escherichia coli}

A contagem de coliformes totais e $E$. coli no sorvete de creme foi realizada em Petrifilm ${ }^{T M} 3 M^{\top M}$ EC. As amostras foram incubadas por $24 \pm 2 \mathrm{~h}$ a $35 \pm 1^{\circ} \mathrm{C}$, segundo método AOAC (2002). As amostras de sorvete de creme light destinadas a contagem de $E$. coli foram incubadas por $24 \pm 2 \mathrm{~h}$ a $35 \pm 1^{\circ} \mathrm{C}$ (APHA, 2001).

\subsubsection{Staphylococcus aureus}

A contagem de Staphylococcus aureus no sorvete de creme foi realizada em Petrifilm ${ }^{T M} 3 M^{T M}$ STX. As amostras foram incubadas por $24 \pm 2 \mathrm{~h}$ a $35-37 \pm 1^{\circ} \mathrm{C}$, segundo AOAC 2003.08. Para as amostras de sorvete de creme light a contagem de Staphylococcus aureus foi realizada após incubação de $24 \pm 2 \mathrm{~h}$ a $35-37 \pm 1^{\circ} \mathrm{C}$ (APHA, 2001).

\subsubsection{Salmonella spp}

A confirmação de presença e ausência de Salmonella spp nas amostras de sorvete de creme light foi realizada segundo AOAC (2011), pelo laboratório TECAM acreditado na ISO 17025 com Boas Práticas de Laboratório. 


\subsection{Análise colorimétrica}

As análises de cor foram determinadas por reflectância com um colorímetro Minolta-Chromameter modelo CR400 (Figura 10). O equipamento foi calibrado no modo de calibração D-65 configurado no sistema colorimétrico $L^{*}$, a* e $b^{*}$. A luminosidade, de preto ao branco é representada pelo $L^{*}$, a coordenada cromatográfica de verde até vermelho é representada pelo $a^{*}$, e a coordenada cromatográfica de azul ao amarelo é representada pelo b* (KONICA MINOLTA, 1998).

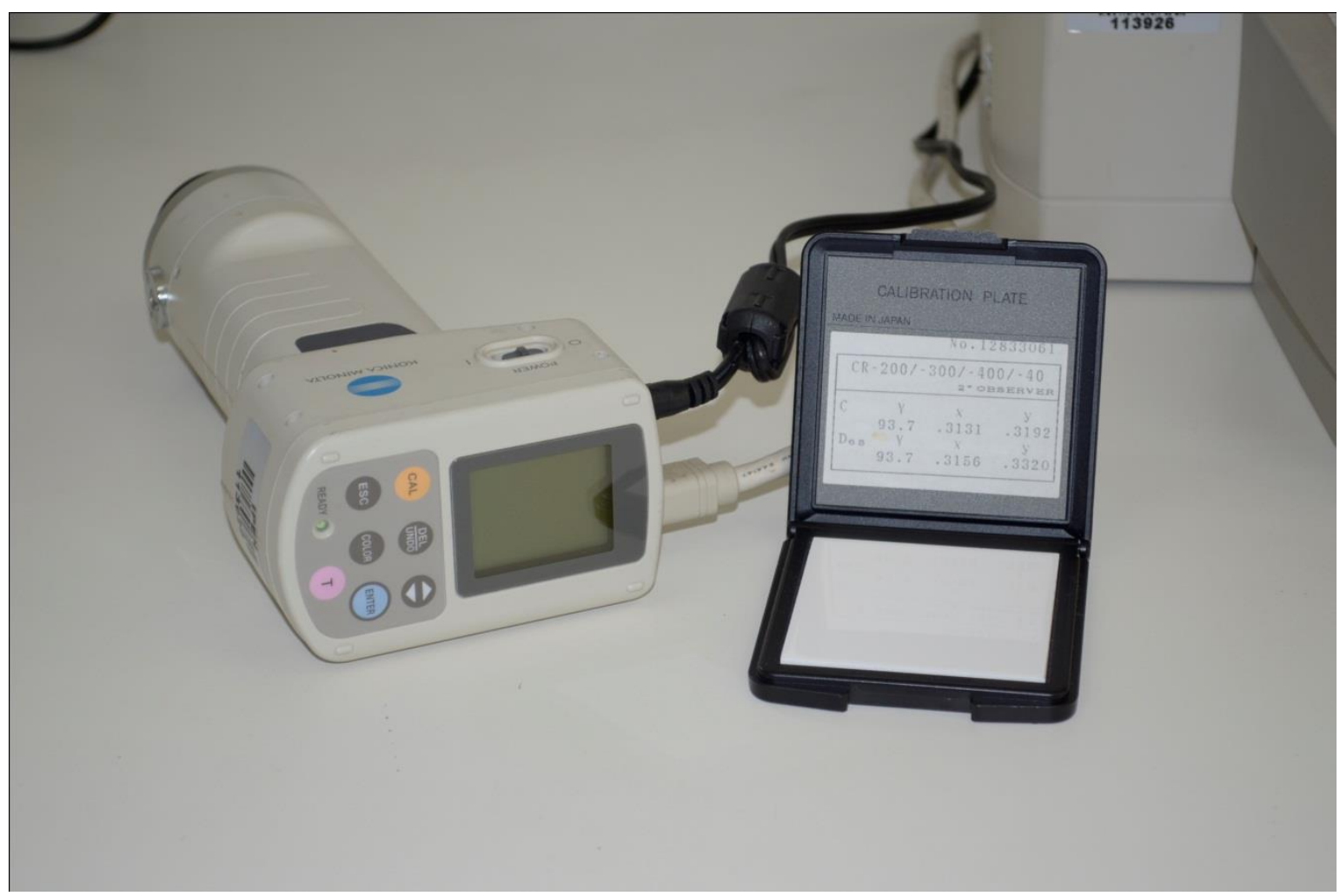

Figura 10. Colorímetro Minolta-Chromameter modelo CR400 instalado no Laboratório de Alimentos do Centro de Tecnologia das Radiações (CTR) do IPENCNEN/USP IPEN-CNEN/USP (Fonte: O próprio autor, 2014). 


\subsection{Análise estatística}

A análise estatística dos resultados foi realizada aplicando-se a análise de variância ANOVA para a presença de efeitos significativos $(p<0,05)$. Neste caso aplicou-se o teste de Tukey para determinar as diferenças entre as médias, por intermédio do software GraphPad Prism 5. 


\section{RESULTADOS E DISCUSSÃO}

\subsection{Análise de cor do sorvete}

Os resultados das análises colorimétricas das amostras de sorvete de creme irradiadas na embalagem de vidro e na embalagem convencional são apresentados na Tabela 5. Na embalagem original pode-se observar que a amostra de 5,0kGy diferiu estatisticamente em relação a controle (parâmetro $L^{*}$ ), sugerindo um leve escurecimento da amostra.

Nas amostras irradiadas na embalagem de vidro pode-se observar uma diferença significativa em relação ao grupo controle (parâmetro $L^{*}$ ). Os valores de $a^{*}$ e $b^{*}$ não diferiram significativamente entre as amostras, tanto na embalagem convencional como na embalagem de vidro.

No entanto, na embalagem de vidro a amostra de 5,0kGy diferiu da amostra controle no parâmetro $a^{*}$, e no parâmetro $b^{*}$ houve diferença estatística entra as amostras controle e irradiadas com 3,0kGy e entre as amostras de 3,0kGy e 5,0kGy. 
Tabela 5. Resultados da análise de cor dos sorvetes de creme irradiados.

\begin{tabular}{cccc}
\hline Dose (kGy) & $\mathbf{L}^{*}$ & $\mathbf{a}^{*}$ & $\mathbf{b}^{*}$ \\
\hline \multicolumn{4}{c}{ Embalagem original } \\
\hline Controle & $89,45 \pm 0,57^{\mathrm{a}}$ & $-0,42 \pm 0,12^{\mathrm{a}}$ & $15,38 \pm 0,36^{\mathrm{a}}$ \\
$\mathbf{3 , 0}$ & $88,49 \pm 0,59^{\mathrm{a}}$ & $-0,49 \pm 0,18^{\mathrm{a}}$ & $15,34 \pm 0,65^{\mathrm{a}}$ \\
$\mathbf{5 , 0}$ & $85,64 \pm 0,80^{\mathrm{b}}$ & $-0,18 \pm 0,09^{\mathrm{a}}$ & $13.87 \pm 0,97^{\mathrm{a}}$ \\
\hline \multicolumn{4}{c}{$\mathbf{E m b a l a g e m ~ d e ~ v i d r o ~}$} \\
\hline $\mathbf{3 , 0}$ & $72,38 \pm 2,41^{\mathrm{a}}$ & $-0,26 \pm 0,29^{\mathrm{a}}$ & $11,80 \pm 1,45^{\mathrm{a}}$ \\
$\mathbf{5 , 0}$ & $79,31 \pm 1,29^{\mathrm{b}}$ & $-0,74 \pm 0,38^{\mathrm{a}}$ & $21,31 \pm 2,32^{\mathrm{b}}$ \\
& $78,53 \pm 0,54^{\mathrm{b}}$ & $-1,19 \pm 0,11^{\mathrm{b}}$ & $16,07 \pm 0,49^{\mathrm{a}}$ \\
\hline a,b & &
\end{tabular}

Nas amostras de sorvete de creme light pode-se observar que a amostra controle e a amostra irradiada com 1,0kGy e 2,0kGy não apresentaram diferença estatística (parâmetro $L^{*}$ ). No entanto, a amostra irradiada com dose de 3,0kGy diferiu tanto em relação ao grupo controle como em relação as amostra irradiadas com 1,0kGy e 2,0kGy (Figura 11). 


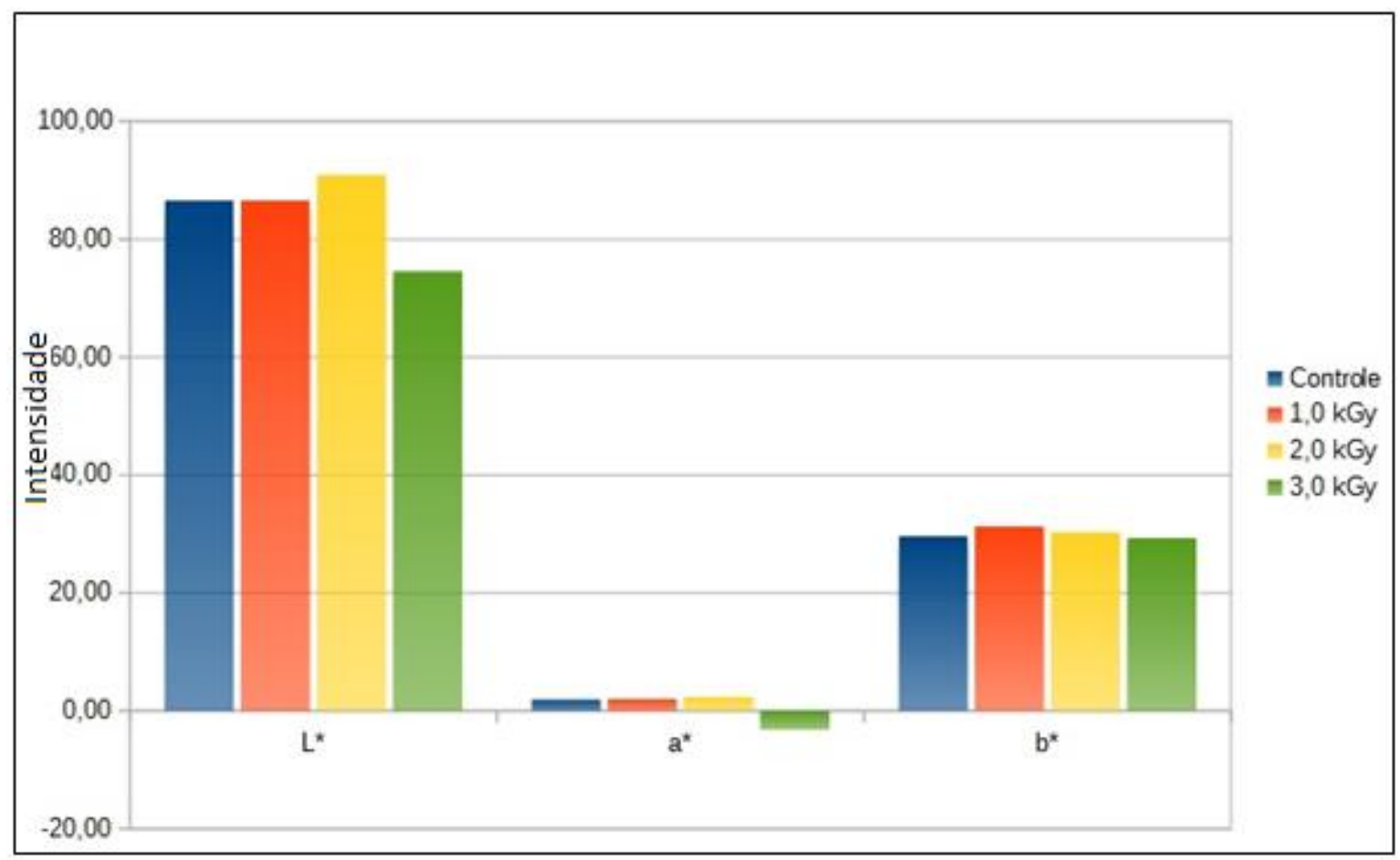

Figura 11. Resultado da análise colorimétrica de sorvete de creme light.

No parâmetro $a^{*}$ somente a amostra irradiada com dose de 3,0kGy apresentou diferença significativa entre as demais amostras. Os resultados do parâmetro $b^{*}$ não apresentaram diferença significativa entre as amostras. Mesmo a análise instrumental demonstrando diferença significativa no parâmetro $a^{*}$, os provadores não observaram diferença na cor do sorvete.

\subsection{Análise sensorial do sorvete}

As amostras de sorvete de creme irradiadas na embalagem de vidro e embalagem original foram submetidas ao Teste Afetivo de Aceitação e os resultados obtidos são apresentados na Tabela 6 . No parâmetro cor não foi observado diferença entre as amostras irradiadas na embalagem de vidro e na embalagem original, embora na análise realizada com o colorímetro essa diferença foi evidenciada na dose de 5,0kGy. 
Em relação ao sabor, foi observada diferença significativa entre o grupo controle e as amostras irradiadas com doses de 3,0kGy e 5,0kGy. No parâmetro textura e aparência global houve diferença significativa entre todas as amostras processadas na embalagem original. A amostra controle, processada na embalagem de vidro diferiu significativamente em relação às amostras irradiadas. No entanto, as amostras de 3,0 e 5,0kGy não apresentaram diferença estatística.

Tabela 6. Média de pontos atribuídos às amostras de sorvete de creme irradiadas.

\begin{tabular}{|c|c|c|c|c|}
\hline Dose (kGy) & Cor & Sabor & Textura & $\begin{array}{c}\text { Aparência } \\
\text { global }\end{array}$ \\
\hline \multicolumn{5}{|c|}{ Embalagem original } \\
\hline Controle & $8,1 \pm 1,1^{\mathrm{a}}$ & $8,0 \pm 1,5^{a}$ & $8,1 \pm 1,0^{a}$ & $8,3 \pm 0,9^{a}$ \\
\hline 3,0 & $7,6 \pm 1,5^{a}$ & $4,8 \pm 2,5^{b, c}$ & $6,9 \pm 1,8^{b}$ & $5,7 \pm 2,3^{b}$ \\
\hline 5,0 & $7,3 \pm 1,7^{a}$ & $4,0 \pm 2,5^{b}$ & $5,5 \pm 2,4^{c}$ & $4,6 \pm 2,4^{c}$ \\
\hline \multicolumn{5}{|c|}{ Embalagem de vidro } \\
\hline Controle & $8,0 \pm 1,4^{a}$ & $8,0 \pm 1,4^{a}$ & $7,7 \pm 1,5^{a}$ & $7,7 \pm 1,7^{a}$ \\
\hline 3,0 & $7,6 \pm 1,4^{a}$ & $6,1 \pm 2,7^{d}$ & $6,3 \pm 2,2^{b}$ & $6,3 \pm 2,3^{b}$ \\
\hline 5,0 & $7,3 \pm 1,8^{a}$ & $5,0 \pm 2,7^{c, d}$ & $6,4 \pm 1,6^{b}$ & $5,3 \pm 2,4^{b}$ \\
\hline
\end{tabular}

Os parâmetros analisados apresentaram similaridade em relação às embalagens originais e de vidro, exceto em relação ao sabor. A média de pontos obtidas na amostra de 3,0kGy foi de 6,1 para a embalagem de vidro, estando acima da nota de corte $(6,0)$ enquanto a dose correspondente na embalagem original obteve uma média de 4,8 .

As amostras irradiadas com 5,0kGy, no parâmetro sabor, apresentaram uma média de 5,0 e 4,0 para a embalagem de vidro e original, respectivamente, enquanto o grupo controle apresentou similaridade, sugerindo que a embalagem 
em que o sorvete é armazenado influencia significativamente o sabor após o processamento por radiação.

Kim et al. (2008) demonstraram que a irradiação de sorvete com doses de 3,0kGy não apresentou diferença significativa na cor, porém essa diferença foi observada no sabor e aparência global, estando em acordo com o presente trabalho. Adeil Pietranera et al. (2003) irradiaram sorvetes com doses de 4,0kGy e reportaram sabores desagradáveis, gosto de queimado e gosto de ranço. No presente estudo alguns painelistas relataram gosto rançoso e gosto de plástico, para ambas as embalagens.

No parâmetro cor não foi observada diferença significativa entre as amostras irradiadas e o grupo controle, porém, nota-se que as amostras irradiadas com dose de 3,0kGy apresentou um ligeiro aumento no grau de satisfação em relação as demais amostras (Tabela 7).

Tabela 7. Resultados da análise sensorial de sorvete de creme light.

\begin{tabular}{cccc}
\hline Controle & \multicolumn{1}{c}{$\mathbf{1 , 0 k G y}$} & $\mathbf{2 , 0 k G y}$ & 3,0kGy \\
\hline \multicolumn{4}{c}{ Cor } \\
$7,07 \pm 1,55^{\mathrm{a}}$ & $6,97 \pm 1,43^{\mathrm{a}}$ & $7,50 \pm 1,50^{\mathrm{a}}$ & $7,53 \pm 1,31^{\mathrm{a}}$ \\
\hline \multicolumn{4}{c}{ Sabor } \\
\hline $7,03 \pm 1,92^{\mathrm{a}}$ & $6,27 \pm 2,03^{\mathrm{a}}$ & $5,63 \pm 1,99^{\mathrm{b}}$ & $6,77 \pm 1,94^{\mathrm{a}}$ \\
\hline a, b & letras diferentes diferem estatisticamente $(\mathrm{p}<0,05)$.
\end{tabular}

Pode-se observar que o grau de satisfação em relação ao parâmetro sabor apresentou diferença significativa somente na amostra de 2,0kGy, que apresentou uma redução de aproximadamente $20 \%$ em relação ao grupo controle. Já as amostras irradiadas com 1,0kGy e 3,0kGy apresentaram uma redução de 10,81\% e 3,70\%, respectivamente, sendo a amostra irradiada com 3,0kGy a mais bem aceita em relação as demais, inclusive o controle, provavelmente devido a 
heterogeneidade dos provadores (Figura 12).

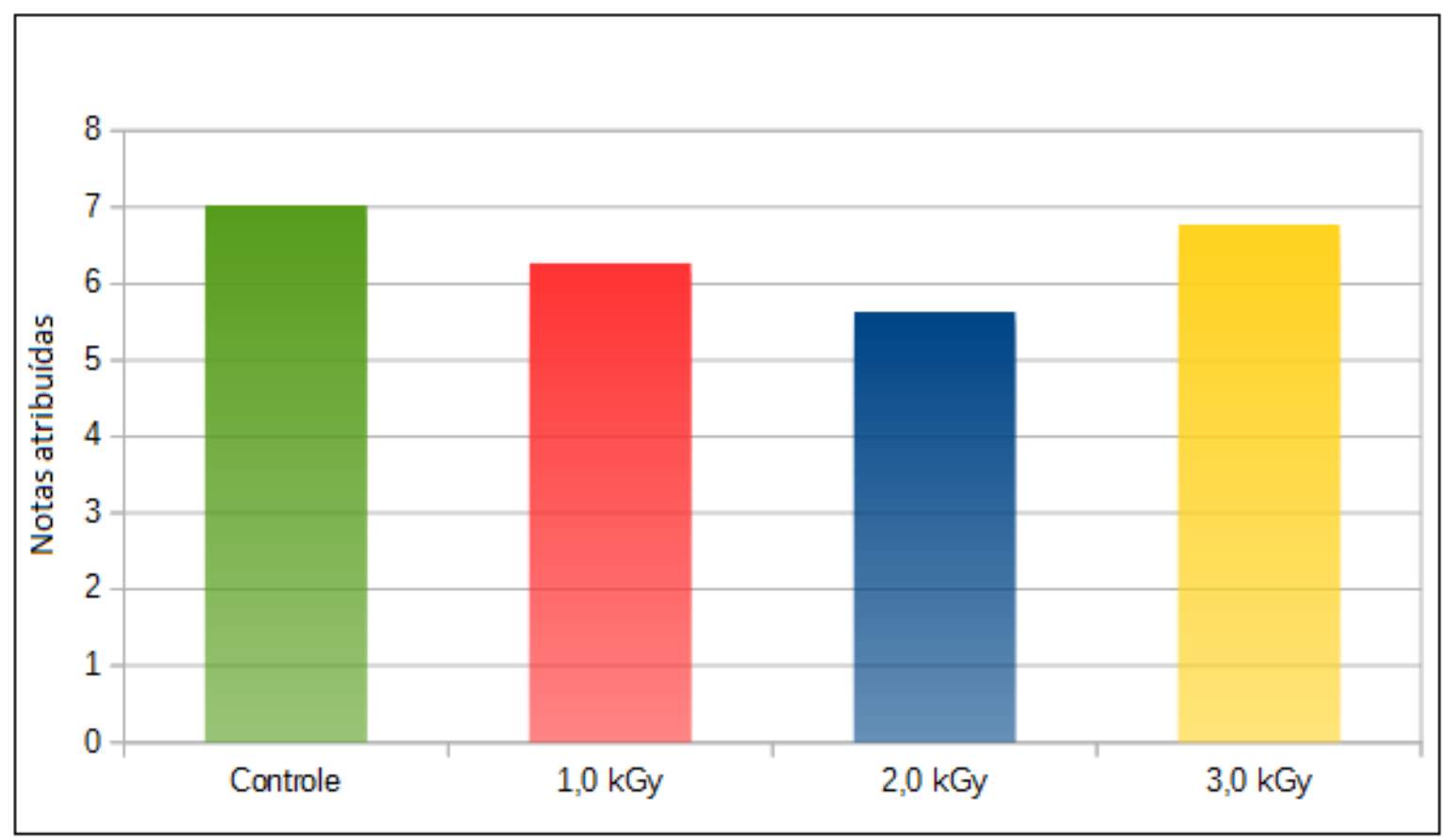

Figura 12. Grau de satisfação do sabor do sorvete de creme light.

\subsection{Análise de textura}

Os resultados das análises de textura demonstram que houve diferença significativa entras as amostras de sorvete de creme light irradiadas com doses de $1,0 \mathrm{kGy}, 2,0 \mathrm{kGy}$ e $3,0 \mathrm{kGy}$ em comparação com as amostras não irradiadas (Tabela 8). No entanto, não foi observado diferença estatística entre as diferentes doses. 
Tabela 8. Resultados de textura de sorvete de creme light, onde DV = desvio padrão.

\begin{tabular}{ccccc}
\hline \multirow{2}{*}{ Amostra } & \multicolumn{4}{c}{ Textura (N) } \\
\cline { 2 - 5 } & Controle & $\mathbf{1 , 0 k G y}$ & $\mathbf{2 , 0 k G y}$ & $\mathbf{3 , 0 k G y}$ \\
\hline & 36,64 & 20,68 & 23,68 & 20,63 \\
Sorvete de & 48,54 & 27,52 & 24,67 & 19,17 \\
creme light & 43,29 & 20,37 & 22,71 & 22,70 \\
& 31,22 & 14,09 & 19,54 & 21,54 \\
& 49,53 & 18,72 & 25,90 & 19,61 \\
\hline Média & 31,77 & 15,44 & 18,24 & 22,70 \\
\hline DV & $\mathbf{4 0 , 1 7 ^ { \mathbf { a } }}$ & $\mathbf{1 9 , 4 7 ^ { \mathbf { b } }}$ & $\mathbf{2 2 , 4 6}{ }^{\mathbf{b}}$ & $\mathbf{2 1 , 0 7 ^ { \mathbf { b } }}$ \\
\hline${ }^{\mathrm{a}, \mathrm{b}}$ letras diferentes entre as colunas diferem estatisticamente $(\mathrm{p}<0,05)$. & $\mathbf{1 , 5 0}$ \\
\hline
\end{tabular}

Oliveira (2005) apresentou um valor de textura de $24,04 \mathrm{~N}$ e $34,38 \mathrm{~N}$ para sorvete de creme e sorvete de creme light, respectivamente, sugerindo que o sorvete light é mais duro em relação ao sorvete tradicional. Isso se explica, pois a gordura melhora a textura do sorvete, fazendo com que o sorvete fique menos resistente (DURSO, 2012).

No presente trabalho a média dos valores de textura foi de $40,17 \mathrm{~N}$ para as amostras não irradiadas, $19,47 \mathrm{~N}$ para as amostras irradiadas com dose de $1,0 \mathrm{kGy}, 22,46 \mathrm{~N}$ para as amostras irradiadas com doses de 2,0kGy e $21,07 \mathrm{~N}$ para as amostras irradiadas com 3,0kGy. Entretanto, Aime et al. (2001) determinaram valores de $90,8 \mathrm{~N}$ para o sorvete convencional e $80,8 \mathrm{~N}$ para o sorvete light.

\section{$5.4 \mathrm{pH}$}

Os valores de $\mathrm{pH}$ não apresentaram diferença entre as amostras controle e irradiadas com doses de 3,0kGy e 5,0kGy (Tabela 9). Os valores de $\mathrm{pH}$ do sorvete estão, geralmente, em torno de 6,3 (ARBUCKLE, 1986), no entanto, dependendo 
do ingrediente adicionado esse valor pode sofrer variação, como por exemplo em sorvete feito com kiwi, que apresenta um valor entre 3,5 e 3,8 (SUNWATERHOUSE et al., 2011), ou mamão, com valores de 5,53 a 5,87 (SANTANA et al., 2003).

Tabela 9. Valores de $\mathrm{pH}$ do sorvete de creme irradiado.

\begin{tabular}{cccc}
\hline Amostra & Controle & $\mathbf{3 , 0 k G y}$ & $\mathbf{5 , 0 k G y}$ \\
\hline \multirow{2}{*}{$\mathbf{p H}$} & $7,06^{\mathrm{a}}$ & $6,99^{\mathrm{a}}$ & $7,13^{\mathrm{a}}$ \\
& $7,07^{\mathrm{a}}$ & $6,99^{\mathrm{a}}$ & $7,10^{\mathrm{a}}$ \\
& $7,12^{\mathrm{a}}$ & $6,98^{\mathrm{a}}$ & $7,00^{\mathrm{a}}$
\end{tabular}

${ }^{a}$ letras diferentes entre as colunas diferem estatisticamente $(p<0,05)$.

\subsection{Sólidos solúveis}

Os resultados do teor de sólidos solúveis ( ${ }^{\circ}$ Brix) não diferiram estatisticamente entre as amostras controle e irradiadas (Tabela 10). A média do ${ }^{\circ}$ Brix foi 39,50, 39,19 e 40,63 para a amostra controle, 3,0kGy e 5,0kGy, respectivamente, estando de acordo com os dados obtidos por Aime et al. (2001), que apresentaram valores similares aos encontrados nesse trabalho. Os valores obtidos por estes autores foram de $38,90^{\circ}$ Brix para as amostras de sorvete convencional, demonstrando que a irradiação com doses de até 5,0kGy não alteram o teor de sólidos solúveis no sorvete utilizado neste trabalho. 
Tabela 10. Valores do teor de sólidos solúveis de sorvete de creme irradiado.

\begin{tabular}{cccc}
\hline Amostras & Controle & $\mathbf{3 , 0 k G y}$ & $\mathbf{5 , 0 k G y}$ \\
\hline \multirow{2}{*}{${ }^{\circ}$ Brix } & $39,26^{a}$ & $37,16^{a}$ & $40,06^{a}$ \\
& $41,26^{a}$ & $39,26^{a}$ & $41,16^{a}$ \\
& $38,06^{a}$ & $41,16^{a}$ & $40,66^{a}$ \\
\hline
\end{tabular}

${ }^{a}$ letras diferentes entre as colunas diferem estatisticamente $(p<0,05)$.

\subsection{Análises microbiológicas}

As análises microbiológicas das amostras de sorvete de creme apresentaram uma redução na contagem de bactérias totais (CBT). Não foi observado crescimento de Staphylococcus aureus, Coliformes Totais e E. coli (Tabela 11), sugerindo que essas amostras estão em conformidade com a legislação vigente (BRASIL, 2001), que estabelece uma contagem máxima de

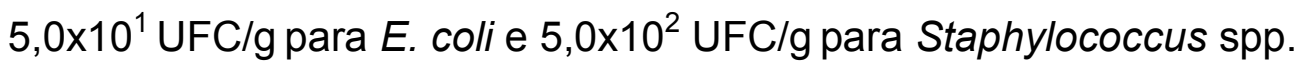

Em um estudo realizado na Líbia, os autores observaram uma contagem de $3,0 \times 10^{1}$ a $3,5 \times 10^{8} \mathrm{UFC} / \mathrm{g}$ para as bactérias totais (CBT); $50 \%$ das amostras foram positivas para E. coli e aproximadamente $49 \%$ das amostras foram positivas para S. aureus (EL-SHARED et al., 2006). Em outro estudo, conduzido por Warke et al. (2000) a contagem de bactéria total foi $9,7 \times 10^{1}$ a $6,0 \times 10^{3} \mathrm{UFC} / \mathrm{g}$. 
Tabela 11. Resultados da análise microbiológica de sorvete de creme antes e após a irradiação.

\begin{tabular}{|c|c|c|c|c|}
\hline $\begin{array}{l}\text { Dose } \\
\text { (kGy) }\end{array}$ & CBT (UFC/g) & S. aureus & Coliformes totais & E. coli \\
\hline Controle & $6,4 \times 10^{1 a}$ & $\begin{array}{c}\text { Abaixo do limite de } \\
\text { detecção }\end{array}$ & $\begin{array}{c}\text { Abaixo do limite de } \\
\text { detecção }\end{array}$ & $\begin{array}{c}\text { Abaixo do limite de } \\
\text { detecção }\end{array}$ \\
\hline 1,0 & $2,7 \times 10^{1} a$ & $\begin{array}{c}\text { Abaixo do limite de } \\
\text { detecção }\end{array}$ & $\begin{array}{c}\text { Abaixo do limite de } \\
\text { detecção }\end{array}$ & $\begin{array}{c}\text { Abaixo do limite de } \\
\text { detecção }\end{array}$ \\
\hline 2,0 & $1,9 \times 10^{1 a}$ & $\begin{array}{c}\text { Abaixo do limite de } \\
\text { detecção }\end{array}$ & $\begin{array}{c}\text { Abaixo do limite de } \\
\text { detecção }\end{array}$ & $\begin{array}{c}\text { Abaixo do limite de } \\
\text { detecção }\end{array}$ \\
\hline 3,0 & $0,6 \times 10^{1 b}$ & $\begin{array}{l}\text { Abaixo do limite de } \\
\text { detecção }\end{array}$ & $\begin{array}{c}\text { Abaixo do limite de } \\
\text { detecção }\end{array}$ & $\begin{array}{c}\text { Abaixo do limite de } \\
\text { detecção }\end{array}$ \\
\hline 4,0 & $0,5 \times 10^{1 b}$ & $\begin{array}{c}\text { Abaixo do limite de } \\
\text { detecção }\end{array}$ & $\begin{array}{c}\text { Abaixo do limite de } \\
\text { detecção }\end{array}$ & $\begin{array}{c}\text { Abaixo do limite de } \\
\text { detecção }\end{array}$ \\
\hline
\end{tabular}

Com o aumento da dose de radiação a contagem de bactérias totais (CBT) foi reduzida para $57,81 \%, 29,69 \%, 9,38 \%$ e $7,81 \%$ após a irradiação com doses de 4,0kGy, 3,0kGy, 2,0kGy, e 1,0kGy, respectivamente. Somente as doses de 3,0 e 4,0kGy diferiram significativamente da amostra controle.

Em um estudo realizado por Kamat et al. (2003) foi observado uma redução de dois ciclos logarítmicos (logs) na contagem de bactérias totais (CBT) com a aplicação da dose de 2,0kGy.

De acordo com a RDC $12 / 01$, os limites máximos para Coliformes a $45^{\circ} \mathrm{C}$, Estafilococos coagulase positiva/g e Salmonella spp/25g são de $5 \times 10^{1} \mathrm{UFC} / \mathrm{g}$, $5 \times 10^{2} \mathrm{UFC} / \mathrm{g}$ e ausência, respectivamente, demonstrando que o sorvete de creme utilizado neste trabalho está em acordo com a legislação brasileira. 


\subsubsection{Staphylococcus aureus}

A Tabela 12 apresenta os resultados obtidos nas amostras controle e amostras irradiadas de sorvete de creme light inoculados com S. aureus. Com a aplicação da dose de 1,0kGy a carga inicial de $S$. aureus foi reduzida em 3,0 ciclos logarítmicos. Com a aplicação de doses de 2,0kGy e 3,0kGy a concentração inicial do microrganismo foi reduzida a níveis não detectáveis, sugerindo uma baixa radio-resistência do $S$. aureus.

Tabela 12. Resultados de sorvete de creme light inoculado com S. aureus.

\begin{tabular}{ccc}
\hline Amostras & Controle (UFC/g) & $\mathbf{1 , 0 k G y ~ ( U F C / g ) ~}$ \\
\hline A1 & $1,8 \times 10^{5}$ & $2,0 \times 10^{2}$ \\
A2 & $1,8 \times 10^{5}$ & $1,0 \times 10^{2}$ \\
A3 & $1,8 \times 10^{5}$ & $1,0 \times 10^{2}$ \\
\hline Amostras & Controle (UFC/g) & $\mathbf{2 , 0 k G y ~ ( U F C / g )}$ \\
\hline B1 & $1,9 \times 10^{5}$ & $<1,0 \times 10^{2}$ \\
B2 & $1,9 \times 10^{5}$ & $<1,0 \times 10^{2}$ \\
B3 & $1,9 \times 10^{5}$ & $<1,0 \times 10^{2}$ \\
\hline Amostras & Controle (UFC/g) & $\mathbf{3 , 0 k G y ~ ( U F C / g )}$ \\
C1 & $1,3 \times 10^{5}$ & $<1,0 \times 10^{2}$ \\
C2 & $1,3 \times 10^{5}$ & $<1,0 \times 10^{2}$ \\
C3 & $1,3 \times 10^{5}$ & $<1,0 \times 10^{2}$ \\
\hline
\end{tabular}

Em um estudo com sorvete conduzido por Kamat et al. (2003) foi observado uma redução de um ciclo logarítmico após a irradiação com dose de 
1,0kGy, partindo de $1,9 \times 10^{3} \mathrm{UFC} / \mathrm{g}$ para $6,0 \times 10^{2} \mathrm{UFC} / \mathrm{g}$, estando em desacordo com os dados obtidos no presente trabalho.

\subsubsection{Escherichia coli}

Pode-se observar que a irradiação foi efetiva na redução da concentração inicial de $E$. coli na ordem de 5,0 ciclos logarítmicos para as amostras irradiadas com dose de 1,0kGy, e a níveis não detectáveis após a irradiação com as doses de 2,0 e 3,0kGy (Tabela 13).

Tabela 13. Resultados de sorvete de creme light inoculado com E. coli.

\begin{tabular}{ccc}
\hline Amostras & Controle (NMP/g) & $\mathbf{1 , 0 ~} \mathbf{~ G y ~ ( N M P / g ) ~}$ \\
\hline A1 & $2,4 \times 10^{6}$ & $3,6 \times 10^{1}$ \\
A2 & $2,4 \times 10^{6}$ & $3,6 \times 10^{1}$ \\
A3 & $2,4 \times 10^{6}$ & $3,6 \times 10^{1}$ \\
\hline Amostras & Controle (NMP/g) & $\mathbf{2 , 0 ~} \mathbf{~ G y ~ ( N M P / g )}$ \\
B1 & $9,3 \times 10^{6}$ & $<3$ \\
B2 & $9,3 \times 10^{6}$ & $<3$ \\
B3 & $9,3 \times 10^{6}$ & $<3$ \\
\hline Amostras & Controle (NMP/g) & $\mathbf{3 , 0} \mathbf{~ k G y ~ ( N M P / g )}$ \\
C1 & $2,4 \times 10^{6}$ & $<3$ \\
C2 & $2,4 \times 10^{6}$ & $<3$ \\
C3 & $2,4 \times 10^{6}$ & $<3$ \\
\hline
\end{tabular}

De acordo com trabalho realizado por Kamat et al. (2003) a carga microbiana de sorvete irradiado foi reduzida de $2,0 \times 10^{3} \mathrm{UFC} / \mathrm{g}$, carga inicial, para 


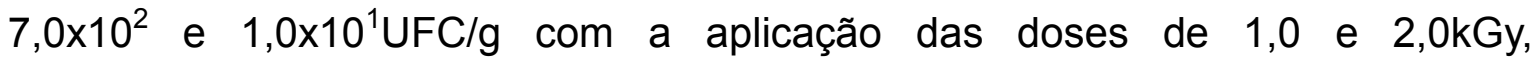
respectivamente.

Entretanto, JO et al. (2007) não obtiveram resultados similares aos obtidos neste trabalho uma vez que a redução foi de somente 4,0 ciclos logarítmicos, partindo de $3,15 \times 10^{6} \mathrm{UFC} / \mathrm{g}$ para $1,5 \times 10^{2} \mathrm{UFC} / \mathrm{g}$ com a aplicação da dose de $1,0 \mathrm{kG}$, enquanto neste trabalho a concentração inicial foi reduzida a níveis não detectáveis. O mesmo autor somente chegou a níveis não detectáveis após a irradiação com dose de 3,0kGy, provavelmente pela diferença de formulação do sorvete e condições de análise.

\subsubsection{Contagem de Bactérias Totais (CBT)}

Pode-se observar que a irradiação das amostras de sorvete de creme light com dose de 1,0kGy reduziu 4 ciclos logarítmicos a concentração inicial de bactérias aeróbias mesófilas (CBT). Com o aumento da dose de radiação, a redução foi de 5 ciclos logarítmicos para as amostras irradiadas com 2,0kGy e a níveis não detectáveis para as amostras irradiadas com dose de 3,0kGy (Tabela 14). 
Tabela 14. Resultados da Contagem de Bactérias Totais (CBT) em sorvete de creme light.

\begin{tabular}{ccc}
\hline Amostras & Controle (UFC/g) & $\mathbf{1 , 0 k G y ~ ( U F C / g ) ~}$ \\
\hline A1 & $2,1 \times 10^{6}$ & $6,7 \times 10^{2}$ \\
A2 & $2,1 \times 10^{6}$ & $3,4 \times 10^{2}$ \\
A3 & $2,1 \times 10^{6}$ & $2,4 \times 10^{3}$ \\
\hline Amostras & Controle (UFC/g) & $\mathbf{2 , 0 k G y ~ ( U F C / g ) ~}$ \\
\hline B1 & $1,7 \times 10^{6}$ & $1,0 \times 10^{1}$ \\
B2 & $1,7 \times 10^{6}$ & $<1,0 \times 10^{1}$ \\
B3 & $1,7 \times 10^{6}$ & $4,0 \times 10^{1}$ \\
\hline Amostras & Controle (UFC/g) & $\mathbf{3 , 0 k G y ~ ( U F C / g ) ~}$ \\
\hline C1 & $1,2 \times 10^{6}$ & $<1,0 \times 10^{1}$ \\
C2 & $1,2 \times 10^{6}$ & $<1,0 \times 10^{1}$ \\
C3 & $1,2 \times 10^{6}$ & $<1,0 \times 10^{1}$ \\
\hline
\end{tabular}

Estes resultados estão de acordo com um estudo conduzido por JO et al. (2007), que também demonstraram uma redução a níveis não detectáveis da concentração inicial de bactérias totais (CBT) com a dose de 3,0kGy, demonstrando a eficiência da irradiação para reduzir a quantidade de bactérias aeróbias mesófilas.

Entretanto, em um estudo realizado por Adeil Pietranera et al. (2003) a carga inicial de bactérias aeróbias reduziu 3 ciclos logarítmicos com a aplicação de 3,0kGy. Kamat et al. (2003) observaram uma redução de apenas 2 ciclos logarítmicos após a irradiação com dose de 2,0kGy. 


\subsubsection{Salmonella spp}

As amostras de sorvete de creme light foram inoculadas com uma concentração de $10^{6} \mathrm{UFC} / \mathrm{g}$ de Salmonella spp. De acordo com a Resolução RDC 12/01 os resultados da análise de Salmonella spp devem ser expressos em ausência ou presença em $25 \mathrm{~g}$ de amostra (BRASIL, 2001).

Pode-se observar que as doses aplicadas não foram suficientes para reduzir a concentração inicial de Salmonella spp em níveis não detectáveis (Tabela 15), sugerindo que a alta carga inoculada pode ter influenciado nos resultados obtidos.

Tabela 15. Resultados de sorvete de creme light inoculado com Salmonella spp.

\begin{tabular}{ccc}
\hline Amostras & Controle $\mathbf{( 2 5 g )}$ & $\mathbf{1 , 0 k G y ~ ( 2 5 g )}$ \\
A1 & Presença & Presença \\
A3 & Presença & Presença \\
\hline Amostras & Presença & Presença \\
\hline B1 & Controle (25g) & $\mathbf{2 , 0 k G y ~ ( 2 5 g )}$ \\
B2 & Presença & Presença \\
B3 & Presença & Presença \\
\hline Amostras & Presença & Presença \\
\hline C1 & Controle (25g) & $\mathbf{3 , 0 k G y ~ ( 2 5 g ) ~}$ \\
C2 & Presença & Presença \\
C3 & Presença & Presença \\
\hline
\end{tabular}


Segundo Patterson (2005) Salmonella spp está entre as bactérias mais resistentes à radiação. Em um estudo realizado por JO et al. (2007) foi demonstrado que a irradiação com dose de 1,0kGy foi suficiente para reduzir a carga inicial de Salmonella spp de $4,0 \times 10^{3} \mathrm{UFC} / \mathrm{g}$ a níveis não detectáveis.

Deve-se notar que a carga inoculada $\left(10^{3}\right)$ por JO et al. (2007) é a metade da carga microbiana inoculada neste trabalho, que teve como objetivo verificar se a irradiação seria efetiva caso um surto de doença de origem alimentar, que não é esperado, ocorresse. 


\section{CONCLUSÃO}

De acordo com os dados obtidos neste trabalho, conclui-se que:

- A irradiação de sorvete de creme light com dose de 3,0kGy foi suficiente para reduzir a níveis não detectáveis a maioria dos microrganismos inoculados;

- Alterações colorimétricas foram observadas nas diferentes doses de radiação empregadas;

- A textura sofreu alteração com o uso da irradiação;

- O sorvete de creme light irradiado com dose de 3,0kGy foi o de melhor aceitação pelo público consumidor. 


\section{REFERÊNCIAS BIBLIOGRÁFICAS}

ADEIL PIETRANERA, M.S.; NARVAIZ, P.; HORAK, P.; KAIRIYAMA, E. Irradiated icecreams for immunosuppressed patients. Radiation Physics and Chemistry, v. 66 , p. 357-365, 2003.

AHAMED, A.A.H.; MOUSTAFA, M.K.; MARTH, E.H. Incidence of Bacillus cereus in milk and some milk products. Journal of Food Protection, v. 46, p. 126-130, 1983.

AIME, D.; ARNTFIELD, S.; MALCOLMSON, L.; RYLAND, D.Textural analysis of fat reduced vanilla ice cream products. Food Research International, v. 34, p. 237-246, 2001.

AMERICAN PUBLIC HEALTH ASSOCIATION - APHA. Compendium of Methods for the Microbiological Examination of Foods, 2001.

ANON. An outbreak of gastroenteritidis and fever due to Listeria monocytogenes in milk. New England Journal of Medicine, v. 336, p. 100-105, 1997.

ANON. Class I recall made of ice cream bars because of Listeria. Food Chemical News, v. 28, p. 31.

ANON. Ice cream bars recalled. FDA Enforcement Report, v. 25, 1990a.

ANON. Vanilla ice cream recalled. FDA Enforcement Report, v. 7, 1990b.

AQUINO, S. Efeitos da radiação gama no crescimento de Aspergillus flavus produtor de aflatoxinas e no emprego da técnica da reação em cadeia de polimerase (PCR) em amostras de grãos de milho inoculadas artificialmente. 
2003. Dissertação (mestrado) - Instituto de Pesquisas Energéticas e Nucleares, São Paulo.

ARBUCKLE, W.S. Ice Cream. 4. ed. AVI Publishing Company, Inc., Westport, Connecticut, 1986.

ASSOCIAÇÃO BRASILEIRA DA INDÚSTRIA DO SORVETE - ABIS. Produções e consumo de sorvetes no Brasil. Disponível em: <http://www.abis.com.br/estatistica producaoeconsumodesorvetenobrasil.html> Acesso em: 12 nov. 2014.

ASSOCIATION OF OFFICIAL ANALYTICAL CHEMISTS - AOAC. Official methods of Analysis of AOAC International. v. 2, 16. ed. Arlington, VA, USA, 1995.

ASSOCIATION OF OFFICIAL ANALYTICAL CHEMISTS - AOAC. Official methods - Vidas Salmonella (SML). Easy Salmonella Method, 2011 (2011.03)

ASSOCIATION OF OFFICIAL ANALYTICAL CHEMISTS - AOAC. Official Methods of Analysis of Official Analytical Chemists International. 18. ed. Rev. $1,2002$.

BACTERIOLOGICAL ANALYTICAL MANUAL - BAM. Food Sampling and Preparation of Sample Homogenate. 8. ed. Food and Drug Administration, FDA, USA, rev. abr., 2003.

BORSZCZ, V. Implantação do sistema APPCC para sorvetes : aplicação na empresa Kimyto. 2002. Dissertação (mestrado) - Universidade Federal de Santa Catarina, Santa Catarina.

BOURNE, M.C. Texture profile analysis. Food Technology, v. 32, p. 62-66, 1978.

BRASIL. ANVISA - Agência Nacional de Vigilância Sanitária. Resolução $\mathrm{n}^{\circ}$. 266, de 22 de setembro de 2005. Aprova o regulamento técnico para gelados 
comestíveis e preparados para gelados comestíveis. Publicada no D.O.U. Diário Oficial da União; Poder Executivo, de 23 de setembro de 2005.

BRASIL. ANVISA . Agência Nacional de Vigilância Sanitária. Resolução RDC nº 12, de 02 de Janeiro de 2001. Aprova o Regulamento Técnico sobre padrões microbiológicos para alimentos. Publicada no D.O.U. - Diário Oficial da União; Poder Executivo, de 10 de Janeiro de 2001.

CHAMPAGNE, C.P.; LAING, R.R.; ROY, D.; MAFU, A.A. Psychrotrophs in dairy products: their effects and their control. Critical Review in Food Science and Nutrition, v. 34, p. 1-30, 1994.

CHANG, Y.W.; HARTEL, R.W. Development of air cells in a batch ice cream freezer. Journal of Food Engineering, London, v.53, n.1, 2002.

CHAVES, J.B.P.; SPROESSER, R.L. Práticas de laboratório de análise sensorial de alimentos e bebidas. Viçosa, MG.: Universidade Federal de Viçosa, 1993.

CHEN, L. OPARA, U.L. Texture measurement approaches in fresh and processed foods - A review. Food Research International. v. 51, p. 823-835, 2013.

CHUG, K. Salmonella outbreak from ice cream. Indian Pediatrics, v. 33, p. 976$977,1996$.

DANIELS, N.A.; MACKINNION, L.; ROWE, S.M.; BEAN, N.H.; GRIFFIN, P.M.; MEAD, P.S. Foodborne disease outbreaks in United States schools. Pediatrics Infections Disease Journal, v. 21, p. 623-628, 2002.

de CENTORBI, O.P.; GUZMAN, A.C.; de CERADRADO, A.A.; LACIAR, A.L.; ALCARAZ, L.E.; deMILAN, M.C.; de PEDERIVA, N.B. Determination of the sanitary quality and detection of Salmonella spp and Yersinia enterocolitica in ice cream. Revista Argentina de Microbiologia, v. 21, p. 63-69, 1989. 
DIEHL, J.F. Safety of Irradiated Foods: 2. ed. revised and expanded. New York, N.Y.: Marcel Dekker Inc., p. 91-115, 1995.

DJURETIC, T.; WALL, P.; NICHOLS, G. General outbreaks of infectious intestinal disease associated with milk and dairy products in England and Wales: 1992 to 1996. Communicable Disease Report Review, v. 7, p. R41-R45, 1997.

DODHIA, H.; KEARNEY, J.; WARBURTON, F. A birthday party, home-made ice cream, and an outbreak of Salmonella enteritidis phage type 6 infection. Communicable Disease and Public Health, v. 1, p. 31-34, 1998.

DURSO, F.M., Fatores que afetam a vida de prateleira de sorvetes de massas artesanais, Instituto Mauá de Tecnologia, São Caetano do Sul, Brasil (2012).

DUTCOSKY, S.D. Análise sensorial de alimentos. 2. ed. Curitiba, PR: Champagnat, 2007. 239p.

EL-SHAREF, N.; GHENGHESH, K.S.; ABOGNAH, Y.S.; GNAN, S.O.; RAHOUMA. Bacteriological quality of ice cream in Tripoli, Libya. Food Control, v. 17, p. 637641, 2006.

EUROGLACES. Facts and Figures. Disponível em: <http://euroglaces.eu/en/Facts-and-figures/Statistical-report-issued-May-2013> Acesso em: 14 nov. 2014.

FARIA, E.V., YOTSUYANAGI, K. Técnicas de análise sensorial. Campinas, SP: ITAL/LAFISE, 2002. 116p.

FARKAS, J. Irradiation for better foods. Trends Food Science and Technology, v. 17, p. $148-152,2006$.

FDA Filing of food additive petition. Notice U.S. Food and Drug Administration, Federal Reg. v.59, p. 43848-43849, 1994. 
FDA Irradiation in the production, processing, and handling of food. Final rule. U.S. Food and Drug Administration, Fed. Reg. v.50, p. 29658- 29659, 21 CFR part 179, 1985.

FDA Irradiation in the production, processing, and handling of food. Final rule. U.S. Food and Drug Administration, Fed. Reg. v.62, p. 64107-64121, 1997.

FELICIANO, C.P.; GUZMAN, Z.M.; TOLENTINO, L.M.M.; COBAR, M.L.C.; ABRERA, G.B. Radiation-treated ready-to-eat (RTE) chicken breast Adobo for immuno-compromised patients. Food Chemistry, v. 163, p. 142-146, 2014.

FETSCH, A.; CONTZEN, M.; HARTELT, K.; KLEISER, A.; MAASSEN, S.; RAU, J.; KRAUSHAAR, B. Staphylococcus aureus food-poisoning outbreak associated with the consumption of ice-cream. International Journal of Food Microbiology, v. 187 , p. 1-6, 2014.

GOFF, H.D. 65 years of ice cream science. International Dairy Journal, v. 18, p. 754-758, 2008.

GREENWOD, M.H.; ROBERT, D.; BURDEN, P. The occurrence of Listeria species in milk and dairy products a national survey in England \& Wales. International Journal of Food Microbiology, v. 12, p. 197-206, 1991.

HENNESSY, T.W.; HEDBERG, C.W.; SLUTSKER, L. A national outbreak of Salmonella enteritidis infections from ice cream. New England Journal of Medicine, v. 334, p. 1281-1286, 1996.

IDFA. The history of the ice cream. Disponível em: <http://www.idfa.org/newsviews/media-kits/ice-cream/the-history-of-ice-cream> Acesso em: 23 nov. 2014.

INTERNATIONAL ATOMIC ENERGY AGENCY - IAEA. Gamma irradiators for radiation processing. IAEA, Vienna, 2005. 
JO, C.; KIM, H.J.; KIM, D.H.; LEE, W.K.; HAM, J.S.; BYUN, M.W. Radiation sensitivity of selected of pathogens in ice cream. Food Control, v. 18, p. 859-865, 2007.

KAMAT, A.; PINGULKAR, K.; BHUSHAN, B.; GHOLAP, A.; THOMAS, P. Potential application of low dose gamma irradiation to improve the microbiological safety of fresh coriander leaves. Food Control, v. 14, p. 529-537, 2003.

KAMAT, A.S.; NERKAR, D.P.; NAIR, P.M. Bacillus cereus in some Indian foods. Incidence and antibiotic heat and radiation resistance. Journal of Food Safety, v. 10, p. 31-44, 1989.

KANBAKNA, U.; CON, A.H.; AYAR, A. Determination of microbiological contamination sources during ice cream production in Denizli, Turkey. Food Control, v. 15, p. 463-470, 2004.

KIM, J.H.; YOON, S.S. Detection of E. coli O157:H7 and Listeria monocytogenes, and appraisal for microbiological qualities in the commercial frozen yogurt products in Korea. Korea Journal of Food Science Animal Resources, v. 18, p. 63-74, 2008.

KONICA MINOLTA. Comunicação precise da cor. Controle da qualidade da percepção à instrumentação. Konica Minolta Sensing, Inc., 1998.

LANZILLOTTI, R.S.; LANZILLOTTI, H.S. Análise Sensorial Sob o Enfoque da Decisão Fuzzy. Revista de Nutrição, v. 12, p. 145-157, 1999.

MAIA, M.C.A.; GALVÃO, A.P.G.L.K.; DELLA MODESTA, R.C.; PEREIRA JÚNIOR, N. Avaliação sensorial de sorvetes à base de xilitol. Ciência e Tecnologia de Alimentos, v. 28, p. 146-151, 2008.

MANN, E.J. Ice cream, part I. Dairy International, v. 53, p. 13-14, 1988. 
MORAES, I.R. de. O uso da radiação ionizante no controle e prevenção de doenças transmitidas por alimentos. Revista Higiene Alimentar, v. 14, p. 36-39, 2000.

MATTHIAS, D.E.; WILDMOSER, H.; WINDHAB, J.E. Air cell microstructuring in a high viscous ice cream matrix. Colloids and surfaces a: physicochemistry engineering aspect, 2005.

OLIVEIRA, K.H. Comportamento reológico de diferentes tipos de sorvete, Universidade Federal de Santa Catarina, Florianópolis, Brasil (2005).

OLIVEIRA, K.H.; SOUZA, J.A.R.; MONTEIRO, A.R. Caracterização reológica de sorvetes. Ciência e Tecnologia de Alimentos, v. 28, p. 592-598, 2008.

PALUMBO, S.A. Is refrigeration enough to restrain food borne pathogen? Journal of Food Protection, v. 49, p. 1003-1009, 1986.

PATTERSON, M. Food Irradiation: Microbiological Safety and Disinfestation. International Symposium "New Frontier of Irradiated Food and Non-Food Products", 2005.

PATTNI, S.; HANLON, C. Clinical guideline for dietary management of neutropenic patients. University hospitals of Leicester NHS trust. Setembro v. 129, 2010.

PEDNEKAR, M.D.; KAMAT, A.S.; ADHIKARI, H.R. Incidence of Listeria species in milk and milk products. Indian Journal of Dairy Science, v. 50, p. 1-10, 1997.

RADOMYSKI, T.; MURANO, E.A.; OLSON, D.G; MURANO, P.S. Elimination of pathogens of significance in food by low-dose irradiation: a review. Journal of Food Protection, Des Moines, v. 57, p. 73-86, 1994. 
RIBEIRO, M.G.; PINTO, J.P. de A.N.; SILVA, E.O.T.R. Escherichia coli O157:H7 de hambúrguer, leite e outros gêneros alimentícios à colite hemorrágica e síndrome urêmico-hemolítica. Higiene Alimentar, v. 13, p. 66-67, 1999.

SALEH, Y.E.; EL FOULY, M.Z.; KHALIL, M.S.; ABO-STATE, M.A. Incidence and characterization of Bacillus cereus isolated from Egyption foods. Qatar University Science Journal, v. 13, p. 75-80, 1993.

SANTANA, L.R.R.; MATSUURA, F.C.A.U.; CARDOSO, R.L. Genótipo melhorado de mamão (Carica papaya L.): avaliação tecnológica dos frutos na forma de sorvete. Ciência e Tecnologia de Alimentos, v. 23, p.151-155, 2003.

SATIN, M. The case of food irradiation. International Conference of the Agricultural Research Institute, p. 93-110, 1993.

SUN-WATERHOUSE, D.; EDMONDS, L.; WADHWA, S.S.; WIBISONO, R. Producing ice cream using a substantial amount of juice from kiwifruit with green, gold or red flesh. Food Research International, in Press, 2011.

USDA Irradiation in the production, processing, and handling of food. Federal Register. 50:29658, 1985.

VARNAM, A.H.; SUTHERLAND, J.P. Milk and milk products: technology, chemistry and microbiology. London: Chapman \& Hall, 1994, 451p.

WARKE, R.; KAMAT, A.; KAMAT, M.; THOMAS, P. Incidence of pathogenic psychrotrophs in ice creams sold in some retail outlets in Mumbai, India. Food Control, v. 11, p. 77-83, 2000.

WATTS, B.M.; YLIMAKI, G.L.; JEFFERY, L.E.; ELIAS, L.G. Basic sensory methods for good evaluation. Ottawa, ON: International Development Research Centre, 1989. 
WORLD HEALTH ORGANIZATION - WHO. Food borne Listeriosis. World Health Organization. Report of Informal Working Group on Listeriosis, WHO/EHE/FOS, v. 88, Geneva, 1988. 